\title{
LA RECAUDACIÓN DE TRIBUTOS ORDINARIOS POR LA MESA ARZOBISPAL COMPOSTELANA EN LA TIERRA DE SANTIAGO: ALCABALAS, DIEZMOS DE LA MAR Y ALFOLÍES ${ }^{*}$ *
}

\author{
THE COLLECTION OF ORDINARY TAXES FOR THE \\ ARCHEPISCOPAL FROM SANTIAGO DE COMPOSTELA \\ TABLE IN THE LAND OF SANTIAGO: SALES TAXES, \\ TITHES OF THE SEA AND ALFOLÍES.
}

\author{
AMPARO RUBIO MARTÍNEZ
}

\begin{abstract}
Resumen
El presente artículo analiza la percepción de tributos reales de carácter ordinario por la hacienda arzobispal compostelana a fines del siglo XV. En él se estudian tres tipos de impuestos: alcabalas, diezmos de la mar y alfolíes, aunque también se analizan otros procedimientos de detracción de las rentas reales tales como los juros de heredad que la mesa arzobispal compostelana poseía en algunas ciudades, villas y lugares de la tierra de Santiago.
\end{abstract}

\section{Palabras clave}

Rentas reales, reino de Galicia, Reyes Católicos, tierra de Santiago.

\begin{abstract}
The present article analyzes the perception of real tributes of ordinary character by the compostelana archiepiscopal property by the end of century XV. In him three types of taxes study: alcabalas, tithes of the sea and public granaries, although also analyze other procedures of detracción of the real rents such as the rights of perpetual ownership of you inherit that the compostelana archiepiscopal table had in some cities, villas and Earth places of Santiago.
\end{abstract}

Key words

Real rents, kingdom of Galicia, Kings Cato'licos, land of Santiago.

\footnotetext{
${ }^{1}$ Entregado el 19 de diciembre de 2007.

* El presente artículo se inscribe en el marco del proyecto de investigación: "Hacienda real, poder político y sociedad en Castilla (1406-1516)" BHA-2002-03292, dirigido por el Dr. Miguel Ángel Ladero Quesada. La elaboración del trabajo ha contado con la ayuda económica del Ministerio de Educación
} 


\section{INTRODUCCIÓN}

Durante los primeros años del reinado de los Reyes Católicos, la recaudación de una gran parte de las rentas reales por los arrendadores y recaudadores del arzobispo Fonseca dentro de los límites de su señorío jurisdiccional, constituyó sin duda uno de los capítulos más sustanciosos del total de sus ingresos. A fines del siglo XV se confirma el desvío de una parte de las rentas reales a la mesa arzobispal compostelana, no sólo de impuestos ordinarios -alcabalas, diezmos de la mar y alfolíes-, sino también de carácter extraordinario -pedidos o servicios-, determinados juros situados sobre las rentas reales y ciertas dádivas que los reyes otorgaron directamente al arzobispo de Santiago. ${ }^{2}$

Por lo que se refiere a las alcabalas que el arzobispo y su mesa arzobispal recaudan en la tierra de Santiago, no contamos con noticia alguna acerca de su cesión, ni siquiera relativa a las alcabalas de los denominados lugares reguengos que, a finales del siglo XV, constituía uno de los ingresos más habituales de la hacienda arzobispal compostelana. El estudio de la documentación hacendística relativa a los reinados de Juan II y Enrique IV pone de manifiesto que la Hacienda Regia contaba con los ingresos derivados de la recaudación de las rentas reales del señorío eclesiástico de la tierra de Santiago y sólo en determinados momentos parece perderlas. Así debió suceder en los últimos años del reinado de Enrique IV, sobre todo a finales de los años sesenta. El vacío documental que se detecta en estos años se identifica con la enajenación de las rentas reales, especialmente de las alcabalas que, por estos años, se encontraban en manos del prelado compostelano. Durante los primeros años de la década de los setenta se observa una cierta continuidad con respecto a los años anteriores. Efectivamente, un documento fechado en 1476 pone de manifiesto que el arzobispo, Alonso de Fonseca, había encargado a Francisco Maldonado, vecino de Salamanca, arrendar las rentas reales del arzobispado de Santiago y del obispado de Tuy correspondientes a los años 1471-74, las cuales se hallaban en poder de Fernando de Pareja, adelantado del reino de Galicia, que disfrutaba de ellas por merced de Enrique IV. ${ }^{3}$ Por esta vía, el arzobispo Fonseca recuperaba las rentas de alcabalas, diezmos de la mar y alfolíes y otros pechos y derechos de la ciudad de Santiago y de las villas y lugares pertenecientes al señorío de la tierra de Santiago.

\footnotetext{
y Ciencia y de la fundación Caja Madrid en su programa de becas predoctorales. Abreviaturas utilizadas: AGS (Archivo General de Simancas), CMC (Contaduría Mayor de Cuentas), EMR (Escribanía Mayor de Rentas), Exp de Hac (Expedientes de Hacienda), RGS (Registro General del Sello), ACS (Archivo de la Catedral de Santiago) LR (libros de recaudación), C1 (Cuaderno primero), C2 (Cuaderno segundo).

${ }^{2}$ VÁZQUEZ BERTOMEU, M.: La Hacienda arzobispal compostelana: libros de recaudación (1481-83 y 1486-91), La Coruña, 2002, p. 37.

${ }^{3}$ AGS, RGS, Segovia, 14 de septiembre de 1476, fol 628.
} 
Sin embargo, no parece suceder lo mismo con las alcabalas de los denominados lugares reguengos o tierra llana de la tierra de Santiago que el arzobispo y su mesa arzobispal percibían desde tiempos inmemoriales. Durante los primeros años de su reinado, los Reyes Católicos trataron de incorporar a la Hacienda Regia las alcabalas de los reguengos en un proceso general llevado a cabo entre los años 1480-83 con las rentas del señorío eclesiástico y nobiliario. Pero el intento fue inútil, pues el arzobispo continuó con sus pretensiones a las alcabalas de estos lugares, hasta que en 1485, los Reyes Católicos autorizaran al arzobispo, Alonso de Fonseca a recaudar las alcabalas de los reguengos con carácter vitalicio.

La percepción de una parte de los diezmos de la mar por el prelado compostelano tiene su origen en los privilegios concedidos por el monarca Fernando IV a la Iglesia Compostelana. En 1304, Fernando IV otorgaba al arzobispo la mitad de los diezmos de la mar de los puertos de la tierra de Santiago, una concesión a la que se añadiría en 1310 la cantidad de 10.000 mrs. anuales que se detraían de la mitad del diezmo perteneciente a la Corona y que en lo sucesivo pasaría a cobrar el arzobispo en forma de juro de heredad. ${ }^{4}$ Este mismo año, 1304, el monarca cedía a la mesa arzobispal compostelana la mitad de las monedas y servicios con los que los vecinos de la tierra de Santiago debían contribuir a la Hacienda Regia. La cesión de una parte de los pedidos reales a la mesa arzobispal compostelana dará lugar a la patrimonialización y señorialización del impuesto, llegando a constituir una parte de los ingresos habituales de la hacienda del arzobispado. Es conveniente tener presente la base jurídica que autorizaba al prelado a recaudar estos tributos, ya que, en virtud de la misma, se respetaría al arzobispo el derecho a recaudarlos. De otro modo, la inexistencia de privilegios y sus posteriores confirmaciones favorables al prelado garantizarán el embargo inmediato de las rentas reales en la tierra de Santiago. Así, cuando los arrendadores reales llegaron a la tierra de Santiago en 1480, lo primero que hicieron fue embargar aquellos tributos reales que percibía el arzobispo de Santiago sin mostrar privilegio -alcabalas y juros de heredad-, dejando libres aquellos que contaban con una base jurídica más sólida como eran los diezmos de la mar.

El presente trabajo se dedica exclusivamente al estudio de los tributos ordinarios - alcabalas, diezmos de la mar y alfolíes-, que los agentes arzobispales recaudan en las villas, puertos y lugares del arzobispado de Santiago en los últimos decenios del siglo XV, aunque también se presta especial atención a determinados juros de heredad situados sobre las rentas reales de ciertas villas y lugares en la tierra de Santiago.

\footnotetext{
${ }^{4}$ Para el estudio de este tipo de concesiones véase GONZÁLEZ VÁZQUEZ, M.: El Arzobispo de Santiago: una instancia de poder en la Edad Media (1150-1400), La Coruña, 1996 y GONZÁLEZ BALASCH, M. T.: El Tumbo B de la catedral de Santiago de Compostela, Santiago de Compostela, 2004.
} 


\section{LA UNIFICACIÓN DEL ESPACIO FISCAL.}

Las primeras medidas de carácter hacendístico llevadas a cabo por los Reyes Católicos durante los primeros años de su reinado se orientaron a la recuperación de las rentas reales enajenadas en manos de señores laicos y eclesiásticos entre los que figura el arzobispo de Santiago, Alonso de Fonseca. ${ }^{5}$ En el arzobispado de Santiago este proceso de integración de las rentas reales en la organización tributaria de la monarquía comenzó en 1480 y duraría hasta 1483. De este modo, la Hacienda Regia recuperaba con carácter definitivo las rentas reales ordinarias del señorío jurisdiccional del arzobispado de Santiago -abadengos-, y, por otra parte, las relativas a los señoríos nobiliarios con mayor peso político y económico de la tierra de Santiago. Las alcabalas de los lugares reguengos que el arzobispo de Santiago percibía desde tiempo inmemorial pasaron a formar parte de los ingresos de la Hacienda Regia durante estos años, aunque no con carácter definitivo, ya que en 1486, el prelado compostelano recuperaba su derecho a percibirlas en virtud de una merced que le reconocía la facultad para recaudarlas con carácter vitalicio mientras ocupase la sede arzobispal. ${ }^{6}$

En 1480 disponemos de las primeras referencias sobre el valor de las rentas reales de las ciudades, villas y lugares pertenecientes al señorío jurisdiccional de la Iglesia de Santiago, que la documentación denomina abadengos. Entre ellas se incluían la ciudad de Santiago y su tierra, las villas de Muros, Noya y Padrón, Pontevedra, Vigo, Redondela, Finisterre, Puebla del Deán y su término, Cee y Corcubión.

Junto a las rentas de los abadengos, pasaban a la Hacienda Regia las rentas reales de un conjunto de señoríos laicos entre los que se cuentan los siguientes: las tierras de Ruy Sánchez de Moscoso y de su hijo Rodrigo de Moscoso, las de Lope Sánchez de Ulloa que tenía el conde de Monterrey, Sancho de Ulloa, las tierras del conde de Trastámara que habían pasado al conde de Altamira, las de Alvar Páez de Sotomayor que tenía su hijo Pedro Álvarez de Sotomayor, las tierras de Fernán Pérez de Andrade que tenía su hijo Diego de Andrade, las de Payo Gómez de Soto-

\footnotetext{
${ }^{5} \mathrm{La}$ ausencia de información que se aprecia en las fuentes documentales sobre el valor de las rentas reales en la tierra de Santiago con anterioridad a 1480 pone de manifiesto como dichas rentas se encontraban enajenadas en manos del prelado compostelano.

${ }^{6}$ La integración de las alcabalas de los reguengos no resultó fácil pues suscitó la oposición de algunos de los lugares que poseían tal condición. Sobre la resistencia de algunos de ellos a hacer entrega de las rentas de alcabalas a la mesa arzobispal compostelana véase FERNÁNDEZ CORTIZO, C.: "Las alcabalas enajenadas en la provincia de Santiago: los reguengos de la mitra compostelana (S. XVXIX)" en Obradoiro de Historia Moderna, 2 (1993).
} 
mayor que formaban parte del patrimonio de su hija doña Sancha, las tierras de Suero Gómez, las de Gómez Pérez de las Mariñas con el coto de Cinis que ahora poseían sus yernos, Diego de Andrade, Fernán Pérez Parragués y Luis de Acevedo, la tierra de Pedro Bermúdez de Montaos que tenía su hijo Fernando, las tierras que, habiendo pertenecido al conde de Santa Marta, habían pasado recientemente al condado de Monterrey, la tierra de Párraga que había pertenecido a Arias Vázquez de Vaamonde y en 1480 se encontraba en manos de su hijo, Fernán Arias de Saavedra. ${ }^{7}$

Ahora bien, la unidad fiscal que los reyes pretendían llevar a cabo en el arzobispado de Santiago no era posible sin la incorporación de los denominados lugares reguengos y otros lugares de señorío laico que todavía se resistían a hacer entrega de las rentas reales a la monarquía. A principios de los años ochenta, poseían la condición de lugares reguengos el puerto de Cangas y la tierra de Morrazo, Pontesampaio, el puerto de San Xenxo de Padriñán, Fefiñáns, O Grove, Villanueva de Arosa, Palmeira, Villagarcía, Aguiño, Muxía, Malpica, el reguengo y juzgado de Pontevedra con el coto de Poio, Caldas de Reis y Caldas de Cuntis, la merindad de Lobeira, la merindad de Castro de Montes, Tierra de Tabeirós, la merindad de La Barreira, la merindad de Monte Sacro, el Val de Cordeiro, tierra de Quintá, Cruces y Herbón, el juzgado de Noya, el alfoz de Muros, la merindad del coto de Xallas, las Dúas Casas y el coto de Bama, Arzúa con el coto de Serantes y Melide.

A ellos se añadían una serie de lugares de señorío laico que, al igual que los anteriores, todavía en 1480 se resistían a hacer entrega de las rentas reales a los oficiales de la monarquía. Entre ellos figuraban las tierras de doña Urraca de Moscoso (Ferreiros y Salceda con Lavacolla, el puerto de Laxe, Val de Barcia), Posmarcos de Luis de Acevedo, la merindad de Mesía, Cambados y Nogueira de doña María de Ulloa, Villagarcía de García de Camaño, la tierra de Pedro Fernández de Andrade, la tierra de García Díaz de Mesía, la tierra de Juan de Bama, la tierra de Martín Sánchez de las Mariñas, la ciudad de Tuy y la tierra de Sobroso de García Sarmiento. A los lugares reguengos y de señorío laico se añadían los dominios jurisdiccionales de algunas abadías que también escapaban al control de los oficiales reales en 1480: la abadía de Lérez, San Paio de Antealtares, San Pedro de Fora, abadía de Aciveiro, Portas, Saiar, Monteagudo, Moraime, la abadía de San Xusto, el monasterio de San Martiño de Ozón, la encomienda de Moreda, Santa María de Franqueira, Ponte Ulla y Sancti Spíritus. ${ }^{8}$

En este gran proyecto de integración de las rentas reales a la Hacienda Regia, los lugares reguengos constituyeron la gran excepción, sobre todo porque el prela-

\footnotetext{
${ }^{7}$ AGS, EMR, leg 28-I, fol 20.

${ }^{8}$ AGS, EMR, leg 28-II, fol 184.
} 
do compostelano lograba recuperar las alcabalas de estos lugares desde 1485 en adelante.

\section{LAS ALCABALAS DE LOS LUGARES REGUENGOS.}

En un intento de unificar el espacio fiscal, los Reyes Católicos trataron de integrar las rentas reales de los lugares reguengos en el conjunto de ingresos que la Hacienda Real recaudaba en el arzobispado de Santiago, recuperando al mismo tiempo las rentas reales del señorío eclesiástico, ciudades y villas de realengo, lugares reguengos y de señorío laico en un único partido fiscal.

A principios de los años ochenta, el arrendamiento de las alcabalas de los reguengos de la tierra de Santiago se llevaba a cabo junto al de otros tributos de carácter señorial -yantares, luctuosas- u otros impuestos que, a pesar de su origen real, comportaban ciertas características de tributo señorial como eran los servicios que el prelado compostelano recaudaba en la tierra de Santiago.

En 1480, los agentes del arzobispo Alonso de Fonseca se encontraban recaudando las alcabalas de los lugares reguengos en la tierra de Santiago. Por otra parte, este año habían llegado a la tierra de Santiago los recaudadores reales exigiendo el pago de alcabalas en cada uno de los lugares reguengos. Aunque el embargo oficial de las rentas reales de la tierra de Santiago no tuvo lugar hasta 1483, la presencia de los oficiales reales desde 1480, trajo como consecuencia el embargo efectivo de las alcabalas a partir de este año. La presencia simultánea del arrendador y recaudador real y de los agentes arzobispales en la tierra de Santiago generó un gran conflicto en torno a la recaudación de las alcabalas de los lugares reguengos. Desde 1480 en adelante, se constata la presencia de oficiales reales en la tierra de Santiago dificultando la recaudación de alcabalas que los tesoreros arzobispales llevaban a cabo en los lugares reguengos. Del mismo modo, la presencia de los fieles del arzobispo en los lugares reguengos de la tierra de Santiago dificultaba considerablemente la labor recaudatoria de Ruy Martínez de Carballido, arrendador y recaudador mayor de las rentas reales del arzobispado de Santiago, que por estos y otros motivos, solicitaba determinados descuentos en el cargo de las rentas del arzobispado de los años 1480-83. Ruy Martínez de Carballido, señalaba que su arrendamiento había incluído las alcabalas de los lugares reguengos, señoríos laicos y abadengos, aunque no se hubiera declarado en los libros de contadores. Ante la dificultad que entrañaba el problema planteado por el recaudador real, los reyes decidían delegar el asunto en una comisión formada por el Prior del Prado, fray Hernando de Talavera y por los doctores de Alcocer y Villalón para que actuasen con justicia. 
La documentación de la Escribanía Mayor de Rentas no nos permite conocer el valor de las alcabalas que los oficiales reales recaudaron en los reguengos de la tierra de Santiago en 1480. Seguramente, los arrendadores y recaudadores reales habrían recaudado una mínima parte del valor de las alcabalas de los lugares reguengos, ya que, cuando llegaron a la tierra de Santiago, una parte de la población de estos lugares habría hecho entrega de las alcabalas y servicios a la mesa arzobispal compostelana y, por otra parte, los reyes habían mandado embargar las alcabalas de los lugares reguengos de 1480, de modo que durante los dos primeros tercios de este año, Carballido no había podido recaudar las rentas de estos lugares. Por consiguiente, Ruy Martínez de Carballido habría logrado recaudar una pequeña proporción de lo que en realidad valdrían las rentas este año. Así se deduce de la famosa sentencia del Prior del Prado, en la que se decidía cargar al arrendador y recaudador real, Ruy Martínez de Carballido, 175.000 mrs. por las rentas de los lugares reguengos que había recaudado junto al resto de los lugares de señorío laico. ${ }^{9}$

A partir de 1481, los tesoreros arzobispales encontraron mayores dificultades para recaudar las rentas reales en los lugares reguengos de la tierra de Santiago, teniendo en cuenta que las exigencias de los oficiales reales a la población de estos lugares eran mayores que el año anterior. ${ }^{10} \mathrm{El}$ primero de los cuadernos de recaudación pone de manifiesto que de todas las localidades que poseían esta condición, únicamente hicieron entrega de las alcabalas a la hacienda arzobispal dos de ellas: Pontesampaio y la tierra y el coto de Xallas. El resto de los lugares no pagaron las alcabalas al arzobispo ante las exigencias del recaudador real. Lo que no sabemos con seguridad es si, efectivamente, Ruy Martínez de Carballido llegó a recaudar las alcabalas de estos lugares. Pensamos que fue así pues estaba dentro de los planes de la monarquía, aunque la recaudación no se hubiese llevado hasta sus últimas consecuencias y de ahí los descuentos que se aplicaron en el cargo de Carballido durante estos años.

En 1481, se acordaba cargar a Carballido $225.000 \mathrm{mrs}$. por las rentas de los lugares reguengos, señoríos laicos y eclesiásticos que habían entrado en su arrendamiento, y que no se habían declarado en los libros de contadores. Aunque la sentencia del prior dejaba claro que, en 1481, no había habido mengua de justicia en

\footnotetext{
${ }^{9}$ AGS, EMR, leg 28-I, fols 20, 24 y 25, leg 29, fols 2 y 3, leg 30, fols 24 y 30 y leg 35, fol 80.

${ }^{10}$ A partir de 1481, contamos con una fuente de estudio de valor apreciable: los cuadernos de recaudación de la mesa arzobispal compostelana. El primero de ellos detalla los ingresos de la mesa arzobispal en concepto de alcabalas de los años 1481 y 1482, mientras que en el segundo se registran los valores de las alcabalas que el prelado compostelano percibía en concepto de deudas de los años 1480-86 y, del mismo modo, el valor de las alcabalas de los lugares reguengos de los años 1487-91.
} 
el reino de Galicia, cabe pensar que este año tampoco se había conseguido recaudar todo lo que correspondía por las rentas de los lugares reguengos, señoríos laicos y eclesiásticos, pues esta cantidad resulta muy exigua si se compara con el valor en el que el año siguiente Luis de Valera arrendaba las rentas de estos lugares. ${ }^{11}$

Conocemos la cuantía que en 1481 la tierra y el coto de Xallas y Pontesampaio habían pagado a la hacienda arzobispal en concepto de alcabalas y otros tributos o lo que es lo mismo, la exigua cantidad que en esta fecha había escapado al control del recaudador real. Ahora bien, estas cuantías no son exactas, teniendo en cuenta que las alcabalas de Pontesampaio se arrendaban junto al portaje y otros derechos de carácter señorial y la tierra y el coto de Xallas hacía entrega de $10.000 \mathrm{mrs}$. al tesorero arzobispal en concepto de servicios y alcabalas.

\section{Tabla 1: Alcabalas y servicios y otros derechos $(1481)^{12}$}

Lugar

Coto de Bama y Dúas Casas

San Martino de Calvos y San Vicenzo de Arceo

Villa de Melide

Villa de Arzúa

Tierra de Rodeiro

Merindad de Castro de Montes con

Caldevergazo

Tierra de Tabeirós y merindad de la

Barreira

Merindad de Monte Sacro ${ }^{13}$

Tierra de Cordeiro

Tierra de Quintá y Cruces y Herbón
Concepto

Alcabalas y servicio

Alcabalas y servicio

Alcabalas, servicio y carnicería

Alcabalas y servicio

Alcabalas y servicio

Alcabalas, servicio y yantar

Alcabalas y servicio

Alcabalas y servicio

Alcabalas y servicio

Alcabalas y servicio
Cuantía

(mrs)

2.000

8.520

3.333

4.166

9.366

12.790

5.183

4.666

2.833

${ }^{11}$ AGS, EMR, leg 35, fol. 80: la sentencia del Prior del Prado señala lo siguiente “... parecería que se debe pagar al dicho Ruy Martínez de Carballido en cada uno de los dichos dos años de 1480 y 1481 por las alcabalas, diezmos y alfolies de los dichos lugares reguengos y otros señoríos las cuantías siguientes: por el año de 1480, $175.000 \mathrm{mrs}$. y por el dicho año de 1481, $225.000 \mathrm{mrs}$., esto por cuanto en este dicho año no hubo mengua de justicia en el dicho reino de Galicia...." También véase AGS, EMR, leg 29, fols 53 y 54, leg 30, fols 38, 84 y 85 y leg 31, fols 150, 151, 153 y 155.

12 De la relación de lugares que ofrecemos en esta tabla, únicamente hicieron entrega de las alcabalas a los tesoreros arzobispales los habitantes de Pontesampaio que satisfacían las alcabalas junto al portaje que se pagaba en dicho lugar y otras derechuras y la tierra de Xallas que hacía entrega de un total de $10.000 \mathrm{mrs}$.

${ }^{13}$ La merindad de Monte Sacro se compone de las unidades fiscales de San Mamede de Ribadu1la, San Cristovo de Merín, Santa Cruz de Ribadulla, San Pedro de Vilanova, Santa Baia Vedra, Santo André de Illobre, San Miguel de Sarandón, San Pedro de Sarandón y San Breixome de Sergude. 
Caldas de Cuntis

Caldas de Reis con sus reguengos

Pontesampaio

Vilanova de Arousa

Puerto de O Grove

Feligresías de Noia

Alfoz de Muros y merindad de Outes

Tierra y coto de Xallas

Cee

Muxía

Feligresías de Xobre y Lampón

Puerto de Santa Uxía

Feligresía de Santa Uxía

Puerto de Aguiño

Puerto de Palmeira

Malpica y su alfoz
Alcabalas, servicio y yantar

1.833

Alcabalas, servicio y yantar

16.762

Alcabalas, portaje y derechuras

4.230

Alcabalas y servicio

Alcabalas y servicio

Alcabalas

Alcabalas y servicio

Alcabalas y servicio

Alcabalas

Alcabalas

Alcabalas y servicio

Alcabalas y servicio

Alcabalas y servicio

Alcabalas y servicio

Alcabalas y servicio

Alcabalas



En 1482, nos encontramos con la misma situación; los oficiales de la monarquía recaudaron con excesivo cuidado las alcabalas de los lugares reguengos, aunque ignoramos que es lo que ocurrió con las alcabalas de los lugares de señorío laico y eclesiástico. El cuaderno de recaudación correspondiente a este año revela que sólo uno de los lugares reguengos, Pontesampaio, había hecho entrega al tesorero arzobispal de las correspondientes rentas de alcabalas junto a otros derechos de carácter señorial como el portaje. Si cotejamos las cuentas del tesorero arzobispal, Francisco de Treviño, con la documentación real de la Escribanía Mayor de Rentas, observamos que la integración de las alcabalas de los lugares reguengos al aparato hacendístico de la monarquía había resultado relativamente sencilla, aunque no había sucedido lo mismo con las alcabalas de ciertos lugares de señorío laico y eclesiástico.

En 1482, las rentas de los lugares reguengos, señoríos laicos y eclesiásticos se habían arrendado a Luis de Valera en 536.690 mrs. Por otra parte, se daba por hecho que en el arrendamiento de Carballido de este año, habían entrado las alcabalas de estos lugares. De este modo, la sentencia del Prior del Prado acordaba suspender a Carballido 250.000 mrs. por las posibles pérdidas que el arrendamiento paralelo a Luis de Valera hubiera podido ocasionarle. ${ }^{14}$

${ }^{14}$ AGS, EMR, leg 29, fol 226, leg 30, fol 85, leg 31, fol 154, leg 32, fols 54, 55, 56 y 57, leg 33 , fols $50,51,58,59,60$ y 258 y leg 35 , fol 80 . 
Tabla 2: Alcabalas, servicios y otros derechos $(1482)^{15}$

Lugar

Coto de Bama y Dúas Casas

Feligresías de S. Martino de Calvo

y San Vicenzo de Arceo

Villa de Melide

Villa de Arzúa

Tierra de Rodeiro

Castro de Montes con Caldevergazo

Tierra de Tabeirós y merindad de

La Barreira

Merindad de Monte Sacro

Tierra de Cordeiro

Tierra de Quintá y Cruces y Herbón

Caldas de Cuntis

Caldas de Reis con sus reguengos

Pontesampaio

Vilanova de Arousa

Puerto de O Grove

Cuatro feligresías de Noia

Alfoz de Muros y merindad

de Outes

Tierra y coto de Xallas

Cee

Muxía

Feligresías de Xobre y Lampón

Puerto de Santa Uxía

Feligresía de Santa Uxía

Puerto de Aguiño

Puerto de Palmeira

Malpica
Concepto

Alcabalas y servicios

Alcabalas y servicios

Alcabalas, servicio y carnicerías

Alcabalas y servicios

Alcabalas y servicios

Alcabalas, servicio y yantar

Alcabalas y servicios

Alcabalas y servicios

Alcabalas y servicios

Alcabalas y servicios

Alcabalas, servicio y yantar

Alcabalas, servicio y yantar

Alcabalas, portaje y

otras derechuras

Alcabalas y servicios

Alcabalas y servicios

Alcabalas

Alcabalas y servicios

Alcabalas y servicios

Alcabalas

Alcabalas

Alcabalas y servicios

Alcabalas y servicios

Alcabalas y servicios

Alcabalas y servicios

Alcabalas y servicios

Alcabalas
Cuantía

2.000

8.520

3.333

4.166

9.366

12.790

5.183

4.666

2.833

1.833

16.762

4.230

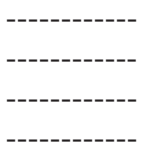

-------------

1 florín/vecino

750

1 florín/morador

1 florín/morador

En 1483, las alcabalas de los lugares reguengos y señoríos laicos las había arrendado Gómez Fernández de Santa Cruz, criado del alcaide de la fortaleza de Bayona, Juan de Sandoval. Una vez más, se pretendía que el arrendamiento pasase a manos de Ruy Martínez de Carballido en un intento de unificar el espacio fiscal y facilitar los trámites de cobro por localidades:

${ }^{15}$ En 1482, únicamente el lugar de Pontesampaio entregaba a los agentes arzobispales los 4.230 mrs. que debía satisfacer en concepto de alcabalas, portaje y otras derechuras. 
“... por manera que de todo el dicho arzobispado de Santiago y obispado de Tuy con los dichos lugares reguengos y señoríos sobre que hay debate se le haga un cuerpo de renta para este dicho presente año de 1483.." 16

Los contadores mayores estimaban el valor de las rentas de los lugares reguengos, señoríos laicos y eclesiásticos de 1483 en 714.891 mrs., cantidad en la que Antonio de Aguilar había rematado las rentas de estos lugares, aunque su postura no hubiera llegado a tener efecto. En relación con la cuantía que este año se debía cargar a Carballido, la sentencia del prior determinaba incrementar su cargo en 238.297 mrs., una tercera parte del valor en el que Antonio de Aguilar había arrendado las rentas este año. ${ }^{17}$

De todo esto se deduce que, en tres años, la monarquía había llevado a cabo sus propósitos en el arzobispado de Santiago: la integración de los diferentes territorios en un único partido fiscal. El proceso se había llevado a cabo con eficacia, aunque no sin dificultades. A partir de 1483 apenas contamos con datos en la documentación que reflejen si los lugares reguengos, señoríos laicos y abadengos continuaron tributando a la monarquía, o si, por el contrario, volvieron a manos del arzobispo. No cabe duda de que la situación había cambiado, aunque el cambio decisivo tendría lugar en 1486, cuando los reyes, ante las quejas del prelado, garantizaron de modo casi vitalicio su derecho a percibirlas y le autorizaran el cobro de las correspondientes a los años 1484 y 1485, al tiempo que se encargaba a los recaudadores reales que pagasen al arzobispo la parte correspondiente a las rentas reales de los lugares reguengos en tanto que el problema se solucionase. ${ }^{18}$ En septiembre de 1485 tenemos constancia de una provisión real por la que los reyes hacían merced al prelado compostelano de modo que "mientras fuera tal arzobispo de Santiago se le acuda con las rentas y alcabalas de los lugares reguengos en la encomienda de ciertos gastos y por algunas cosas cumplideras a mi servicio al tiempo que el rey mi señor y yo teníamos guerra con el rey de Portugal"19

No obstante, el levantamiento de los bienes embargados no se produjo hasta 1486. Concretamente el 10 de abril de 1486 otorgaban una cédula y una provisión real tratando de poner fin al asunto. Por la primera se decretaba el levantamiento del embargo "para que sea acudido al dicho arzobispo con sus maravedís e otras

\footnotetext{
${ }^{16}$ AGS, EMR, leg 35, fol, 80.

${ }^{17}$ AGS, EMR, leg 33, fol 50, leg 35, fols 78, 79, 80 y 247, leg 37, fols 171, 173, 175, 177, 186, 187 y 188.

${ }^{18}$ VÁZQUEZ BERTOMEU, M.: La Hacienda arzobispal...op cit, p. 40.

${ }^{19}$ Provisión real otorgada el 9 de septiembre de 1485 en FERNANDEZ CORTIZO, C.:"Las alcabalas enajenadas...", op cit, p. 136.
} 
cosas que las dichas alcabalas de los dichos reguengos han montado e rendido desde el primero día de enero del dicho ano de ochenta y quatro..." y por la segunda los reyes prometían al prelado que "si se hallase que las alcabalas de los quatro años de ochenta en adelante que le fueron tomados le perteneciere, que se las mandarían pagar.." 20

La ausencia de documentación relativa a estos años nos impide comprobar si la hacienda arzobispal consiguió recuperar el importe correspondiente a las alcabalas de los lugares reguengos de los años 1480-83, pero el segundo libro de recaudación, en su primera parte, refleja el cobro efectivo de las alcabalas de los lugares reguengos durante los años 1484, 1485 y 1486: "Relaçión de los maravedis que yo, el tesorero Nicolás de Azevedo, reçebi de las deudas que se debían al Reverendísimo senor Arzobispo, mi señor, desde el año ochenta fasta en fin del año de ochenta e seys" 21

Tabla 3: Alcabalas de los lugares reguengos. (1480-86)

Localidad/es

Xallas

Fisterra

Feligresías de Noia

Arzúa $^{22}$

Caldas de Cuntis

Reguengos de Pontevedra y coto de Lérez y

coto de San Xoán de Poio y Pontesampaio

con su jurisdicción y coto de los Cobres. ${ }^{23}$

Palmeira

Xobre ${ }^{24}$

Período
$1484-86$
1486
$1484-86$
$1484-86$
1486

1484-86

1486

1484-86
Cuantía

1.860

6.000

15.000

884

2.511

24.505

3.285

3.052

${ }^{20}$ AHDS, FG, leg 70, f.13. Cédula real de fecha 10-4-1486, f. 20, carta y provisión real de fecha 10-4-1486 en FERNÁNDEZ CORTIZO, C.: “Las alcabalas enajenadas...”op cit, p. 136. Sobre la concesión de las alcabalas de los lugares reguengos al arzobispo Alonso de Fonseca, véase AGS, RGS, 23 de septiembre de 1485 , fols 2 y 3.

${ }^{21}$ ACS, C2, fo 3r y 3v en VÁZQUEZ BERTOMEU, M.: La Hacienda arzobispal...op cit, pp. 233234.

${ }^{22}$ En este apartado se señala lo siguiente:'las alcabalas de Tierra de Rodero llevaronlas los arrendadores de sus Altesas del obispado de Lugo, deziendo que no heran reguengos por mandado de sus Altesas quando estuvieron en Santiago e porque el alcalde Mosquera defendió las prendas le tovieron preso en Santiago el alcalde Proano"

${ }^{23}$ Se señala: “...e los Vmill DLXXX maravedis de la feligresía de Santo Andre de Lorençaao, develos porque non los pueden cobrar porque nunca pude hallar forma para los cobrar como reguengos".

24 “las alcabalas del puerto del Caramiñal llevolas Lope Gomes, notario de Santiago por çierto asiento que su señoría tomo con el e mando su señoría que le pagase treynta mill maravedis que yo avía llevado del dicho Lope Gomez” 
A partir del levantamiento del embargo de las alcabalas de los reguengos en 1486, el prelado compostelano comenzó de nuevo a ingresar las cuantías íntegras del valor de las alcabalas. El segundo cuaderno de recaudación detalla los ingresos correspondientes al período 1487-91:

Tabla 4: Alcabalas de los lugares reguengos (1487-91)

\section{Población}

Coto de Xallas

Villa de Malpica y su alfoz

Villa de Muxía

Villa de Fisterra y cotos de Duio y Sardiñeiro

Puerto de Cee

Alfoz de Muros

Cuatro feligresías de Cabo de Noia: Santa Cristina,

coto de Sabardes, San Xoán de Roo con el coto de

San Xusto y Santa María de Argalo y Santa María de

Obre

Coto de Bama y Dúas Casas

Arzúa

Calvos, Arceo, Pantiñobre

Melide

Castro de Montes y Caldevergazo

Tierra de Tabeirós

A Ponte Ulla

Tierra de Cordeiro

Tierra de Quintá, Cruces y Herbón

Villa de Caldas de Reis

Reguengos de la villa de Caldas de Reis y Saniera y

de Caldas de Cuntis

Villa y puerto de Vilanova de Arousa

Puerto de Fefiñanes

Puerto de Sanxenxo

O Grove

Reguengos de Pontevedra y coto de Poio y San Fiis y

Pontesampaio con su jurisdicción y coto de los Cobres

Puerto de Aguiño

Feligresía de Santa Uxía

Puerto de Santa Uxía

Puerto de Palmeira

Feligresía de Santiago de Lampón

Puerto de Caramiñal

$\begin{array}{lll}\text { Período } & \text { Cuantía } & \text { Mrs/año } \\ 1487-91 & 291.360 & 58.272 \\ 1487-91 & 200.872 & 40.174 \\ 1487-91 & 317.781 & 63.556 \\ 1487-91 & 469.038 & 93.807 \\ 1487-91 & 253.495 & 50.699 \\ 1487-91 & 400.954 & 80.190 \\ 1487-91 & 57.936 & 11.587\end{array}$

$\begin{array}{lll}1487-91 & 39.780 & 7.956 \\ 1487-91 & 47.408 & 9.481 \\ 1487-91 & 30.942 & 6.188 \\ 1487-91 & 72.330 & 14.466 \\ 1487-91 & 122.160 & 24.432 \\ 1487-91 & 168.507 & 33.701 \\ 1491 & 5.000 & 5.000 \\ 1487-91 & 58.082 & 11.616 \\ 1487-91 & 90.199 & 18.039 \\ 1487-91 & 77.597 & 15.519 \\ 1487-91 & 125.976 & 25.125 \\ & & \\ 1487-91 & 334.425 & 66.885 \\ 1487-91 & 36.015 & 7.203 \\ 1487-91 & 25.886 & 5.177 \\ 1487-91 & 236.471 & 47.294 \\ 1487-91 & 118.727 & 23.745 \\ & & \\ 1487-91 & 16.113 & 3.222 \\ 1487-91 & 8.408 & 1.681 \\ 1487-91 & 33.243 & 6.648 \\ 1487-91 & 8.060 & 1.612 \\ 1487-92 & 4.448 & 741 \\ 1487-91 & 30.000 & 6.000\end{array}$

3.681.213 740.016

\section{Total:}


Las cifras que acabamos de exponer nos permiten observar que el valor medio de las rentas de alcabalas de los lugares reguengos por año es de 740.016 mrs., lo que indica que durante estos años el crecimiento del valor de las alcabalas había sido notable ya que, en 1482, las rentas de estos lugares se habían arrendado junto a las de los señorios laicos en 536.690 mrs..$^{25}$

Desde 1486 en adelante, el arzobispo continuó ingresando las rentas de alcabalas de los lugares reguengos, sin embargo el problema planteado en torno al cobro de alcabalas en estos lugares, lejos de resolverse se iba a complicar más aún. La cédula real otorgada por los Reyes Católicos el 10 de abril de 1486, levantó la oposición vecinal que se canalizó fundamentalmente en tres frentes: "los reguengos" de Tabeirós, Castro de Montes y Caldevergazo, el alfoz de Muros y "las cinco Villas". ${ }^{26}$ Las resistencias de estos concejos desembocaron en la oposición al pago de las rentas de alcabalas al arzobispo desde el año 1492. ${ }^{27}$ La rebeldía de estas localidades dio lugar a sucesivas pesquisas que se llevaron a cabo durante los años $1492,1494,1497$ y 1505.

En 1502, los reyes enviaban una provisión real a su gobernador en el reino de Galicia, Fernando de Vega, exponiéndole que, después de haber hecho merced al prelado compostelano para que recaudase libremente las alcabalas de los lugares reguengos, el arzobispo había manifestado la oposición que la merindad de La Barreira y Castro de Montes habían presentado al pago de dichas rentas alegando que no poseían la condición de lugares reguengos. Como solución, los reyes pedían al gobernador averiguar si el arzobispo había recaudado las alcabalas de estos lugares, pues de no ser así, debería obligar a los habitantes de la merindad de La Barreira y Castro de Montes al pago de las alcabalas al arzobispo. ${ }^{28}$

En 1504 continuaba la negativa al pago de las merindades de La Barreira y Castro de Montes. Una nueva provisión real de fecha 13 de agosto de 1504, urgía a las autoridades y concejos de las merindades de La Barreira y Castro de Montes el pago de alcabalas al prelado compostelano. ${ }^{29}$

Similares fueron las decisiones que los reyes tomaron con respecto al alfoz de Muros, en el que los vecinos se negaban a pagar las alcabalas al prelado señalando que no eran reguengos. Por provisión real otorgada en Sevilla el 15 de febrero

\footnotetext{
${ }^{25}$ AGS, EMR, leg 32, fol 56.

${ }^{26}$ FERNÁNDEZ CORTIZO, C.: "Las alcabalas enajenadas..." op cit, p.136.

${ }^{27}$ AHDS, FG, leg 70: "Información y averiguación que hizo el licenciado Tórtoles por comisión de la Reyna Doña Juana y de pedimiento de fiscal real. Passó el año de 1505” en FERNÁNDEZ CORTIZO, C.: "Las alcabalas enajenadas..." op cit, p. 137.

${ }^{28}$ AGS, EMR, leg 86, y leg 85-II, fol. 113.

${ }^{29}$ AGS, EMR, leg 97, f.472 y leg 85, f. 408.
} 
de 1502, los Reyes Católicos pedían a su gobernador en Galicia, Fernando de Vega, que obligase a los concejos de los cotos y feligresías del alfoz de Muros a pagar 77.000 mrs. por cada uno de los siete años pasados que no habían acudido con las alcabalas de estos lugares al arzobispo. ${ }^{30}$

El 8 de septiembre de 1502, los reyes se dirigían a las autoridades del alfoz de Muros exponiendo como, después de haber hecho merced al arzobispo de Santiago para recaudar las alcabalas de los lugares reguengos, los vecinos de alfoz de Muros se habían negado a pagar las alcabalas, alegando que el alfoz no formaba parte de los denominados lugares reguengos y que a ellos no se extendía la merced concedida al arzobispo. Realizadas las pesquisas oportunas, los reyes mandaban embargar las alcabalas de estos lugares de los años pasados (1492-98), y ordenaban a los concejos y alcaldes de estos lugares revisar la merced que el arzobispo de Santiago tenía de las alcabalas de esos lugares, de manera que hasta que no fuese visto y determinado lo que se debía hacer, deberían acudir con las alcabalas al prelado compostelano, no sólo con las relativas al año 1502, sino también con las de los años siguientes. ${ }^{31}$ Una vez más, 9 de septiembre de 1502, los reyes ordenaban que "no obstante de que decían no ser reguengos acudan con las alcabalas al arzobispo" 32

La situación se complicaba aún más teniendo en cuenta que, desde 1499, el alfoz de Muros se había sumado al encabezamiento de alcabalas junto a otras ciudades, villas y lugares del arzobispado de Santiago. Esto explica que la reina hubiese mandado a los contadores mayores expedir las correspondientes cartas de desembargo de las alcabalas del alfoz de Muros con el fin de que los vecinos del lugar entregasen al arzobispo las alcabalas de los años 1499, 1500 y 1501. El 10 de diciembre de 1502, los reyes mandaban a los vecinos de los cotos y feligresías del alfoz de Muros acudir al arzobispo de Santiago con los 77.000 mrs., cantidad en la que se habían encabezado las alcabalas en cada uno de estos tres años. ${ }^{33}$

La misma suerte corrieron los habitantes de las "cinco villas" (Villanueva de Arosa, Finisterre, Malpica, Cee y Puebla del Caramiñal) a las que los arrendadores y recaudadores reales habían embargado las rentas correspondientes a los años 1488-93 dada su resistencia al pago de alcabalas al prelado. Los vecinos de estos lugares se resistían a hacer entrega de alcabalas a la hacienda arzobispal alegando no ser reguengos, pero su intento fue inútil porque la mesa arzobispal siguió

\footnotetext{
${ }^{30}$ AGS, EMR, leg 79, f. 179.

${ }^{31}$ AGS, EMR, leg 86, f. 192 y leg 85-II, f. 1133.

32 Provisión real de fecha 9-9-1502 en FERNANDEZ CORTIZO, C.: "Las alcabalas enajenadas..."op cit p.138.

${ }^{33}$ AGS, EMR, leg 80, f.374.
} 


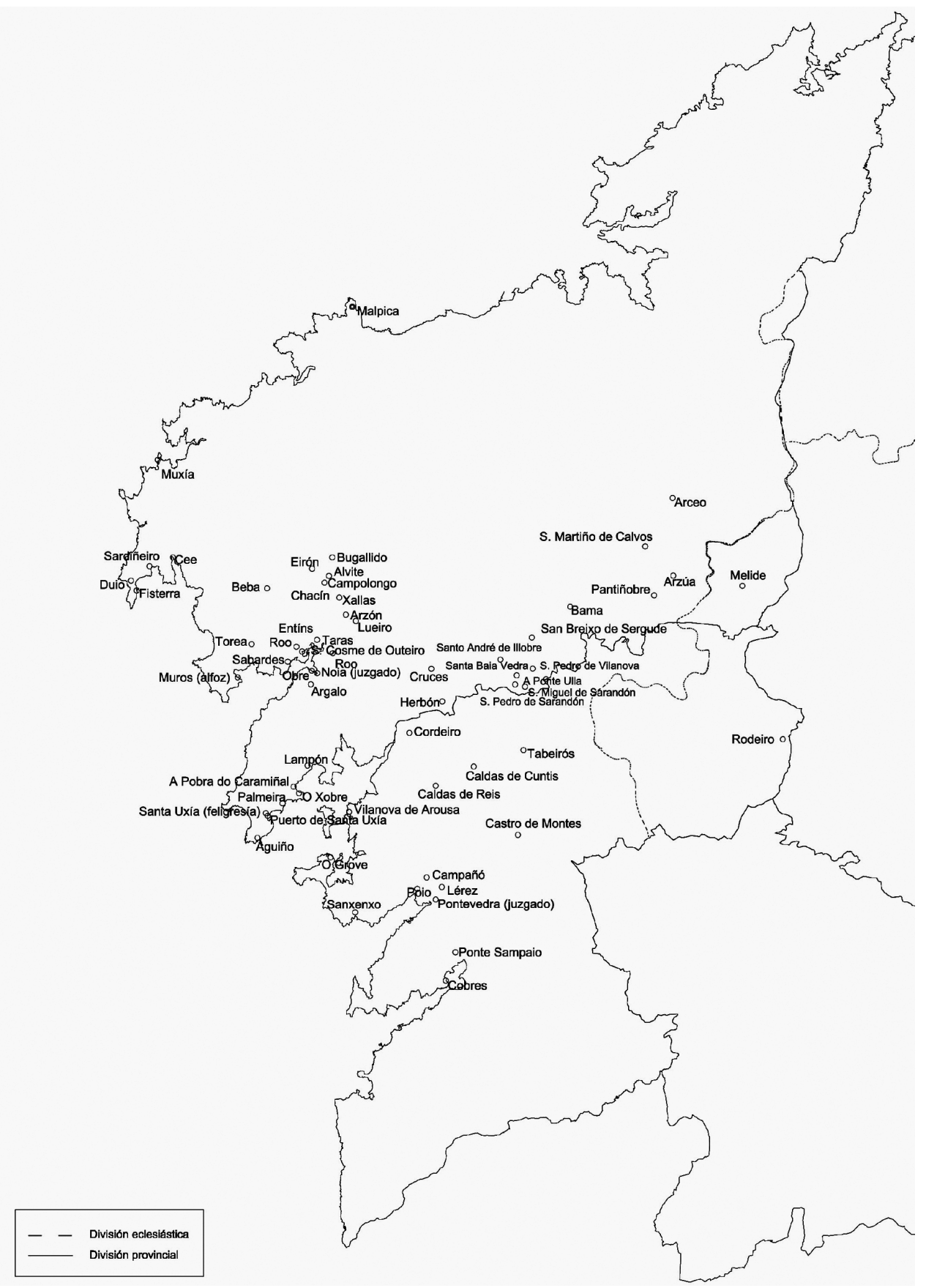

Mapa 1: Alcabalas de los lugares reguengos (1481-1491). 
percibiendo las alcabalas de estas villas hasta que, en 1525, fueron incorporadas a la Corona por Carlos I quien en compensación concedió al arzobispo un juro de 300.000 mrs. en las alcabalas de la ciudad de Santiago. ${ }^{34}$

Todos estos testimonios de oposición al pago de alcabalas al arzobispo por parte de los vecinos de estas villas y lugares y la respuesta insistente de los monarcas de que los respectivos concejos debían acudir con las alcabalas al prelado compostelano, ponen de manifiesto una política de mutuo acuerdo entre la monarquía y el arzobispo. No olvidemos que en 1486 los reyes habían hecho merced a Alonso de Fonseca de las alcabalas de los lugares reguengos a percibir desde 1484 en adelante, tratando de premiar la fidelidad del arzobispo al bando isabelino durante la guerra civil.

\section{DIEZMOS DE LA MAR.}

La percepción de ingresos derivados de una parte de los diezmos de la mar por el prelado compostelano data de 1308, fecha en la que Fernando IV otorgaba al arzobispo la facultad para recaudar la mitad de los ingresos de la denominada diesma de las mercadurías. ${ }^{35}$ Ahora bien, la concesión de la mitad de los diezmos de la mar al prelado compostelano había tenido lugar unos años antes, en 1304. Este año, Fernando IV había concedido al arzobispo la mitad de los diezmos de la mar pertenecientes a la Corona en los puertos de su señorío jurisdiccional, una concesión a la que se añadiría, en 1310, la cantidad de 10.000 mrs. anuales que se detraían de la mitad del diezmo perteneciente a la Hacienda Real y que ahora pasaría a cobrar el arzobispo. ${ }^{36}$

Es posible que la primera concesión de la mitad de los diezmos de la mar al arzobispo hubiese tenido lugar con anterioridad al reinado de Fernando IV. Esto explica que en el fuero de Noya, otorgado en 1168, encontremos ya una mención a la cesión de la mitad del diezmo por parte de la Corona. ${ }^{37}$ En él se señala que todos los ciudadanos de Compostela u otros que allí habitasen o tuviesen casas de morada no pagasen otro pedage que el portazgo y peaje que acostumbraban a pagar las naves. Se especifica también que el monarca se reserva para él y para la Hacienda Regia la mitad de estos ingresos que prometía no ceder a ninguna persona, conde ni caballero, aunque en caso de producirse dicha cesión, ésta se otorgaría en favor del prelado compostelano.

\footnotetext{
${ }^{34}$ FERNÁNDEZ CORTIZO, C.: "Las alcabalas enajenadas...”op cit, p. 138

${ }^{35}$ VÁZQUEZ BERTOMEU, M.: La Hacienda arzobispal.... op cit, p. 41.

${ }^{36}$ GONZÁLEZ VAZQUEZ, M.: El Arzobispo de Santiago...op cit, p 230.

${ }^{37}$ LÓPEZ FERREIRO, A.: Fueros Municipales de Santiago y su tierra, Santiago, 1895-1896. 2 vol Repr. 1975, p.175.
} 
Indudablemente el fuero de Noya constituye el precedente de diversos testimonios documentales de los siglos XIV y XV que ponen de manifiesto que el prelado compostelano era titular de la mitad de los diezmos que ingresaba la Hacienda Regia en los puertos de la tierra de Santiago.

No resulta fácil estimar los ingresos de la mesa arzobispal en concepto de diezmos de la mar ya que, con frecuencia, estos aparecen arrendados junto a los diezmos que gravan la descarga de sal, siendo éste último un tributo que debía guardar cierta relación con los derechos de alfolíes, pertenecientes a la Hacienda Real, que se derivan de la venta de sal que se efectuaba de manera exclusiva en los almacenes de sal o alfolíes, venta que era controlada por los oficiales de la monarquía al tratarse de un monopolio real. ${ }^{38} \mathrm{~A}$ finales del siglo $\mathrm{XV}$, el arzobispo percibe la media diezma de sal y de las mercancías de la mar en los puertos de su señorío jurisdiccional: Padrón, Pontevedra, Villanueva de Arosa, Redondela, Vigo, Cangas, Noya, Muros, Cee, Finisterre, Mugía, y Puebla de Caramiñal. ${ }^{39}$

Según se pone de manifiesto en los libros de recaudación del arzobispado, a principios de los años ochenta había aumentado considerablemente el número de puertos que actuaban como enclaves de carga y descarga de mercancías con respecto a la etapa anterior. Durante el sexenio 1451-56, los cuadernos de arrendamiento mencionan los puertos que funcionan como centros de carga y descarga de manera exclusiva en el reino de Galicia: Bayona de Miño, Pontevedra, Padrón, Muros, Noia, A Coruña y Betanzos, Ribadeo y Navia. ${ }^{40}$ El pago de diezmos de la sal y mercadurías constituía una fuente de ingresos muy notable a fines del siglo XV. Algunos testimonios documentales de estos años ponen de manifiesto la importancia que, en términos económicos, suponía esta fuente de ingresos para la Hacienda Real. Desde principios de los años ochenta, los libros de recaudación arzobispales constatan el pago efectivo de los diezmos de la mar a los tesoreros del arzobispo, lo que se explica fundamentalmente porque el embargo oficial de los diezmos de la mar en los puertos de la tierra de Santiago no tendría lugar hasta 1483.

Un estudio detallado de los cuadernos de recaudación nos permite observar que, durante los años 1481 y 1482, los arrendadores o fieles de las rentas del arzobispo

\footnotetext{
${ }^{38}$ El cuaderno de arrendamiento de los alfolíes (1452) señala que la descarga de sal no estaba sujeta al pago de diezmos, teniendo en cuenta que la venta de sal era regalía de la Corona y por ella la Hacienda Regia percibía los denominados derechos de los alfolíes.

${ }^{39}$ VÁZQUEZ BERTOMEU, M.: La Hacienda arzobispal.... op cit, p 41. (ACS, LR, C1, f. 13v, $15 \mathrm{r}, 15 \mathrm{v}, 16 \mathrm{r}, 16 \mathrm{v}, 17 \mathrm{r}, 17 \mathrm{v}, 18 \mathrm{r}, 19 \mathrm{r}, 20 \mathrm{r}, 25 \mathrm{v}, 27 \mathrm{r}, 27 \mathrm{v}, 28 \mathrm{r}, 28 \mathrm{v}, 29 \mathrm{r}, 29 \mathrm{v}, 30 \mathrm{r}, 31 \mathrm{r}, 32 \mathrm{r}, 38 \mathrm{v}, \mathrm{C} 2$, f. $1 \mathrm{r}, 11 \mathrm{v}, 12 \mathrm{v}, 13 \mathrm{r}, 13 \mathrm{v}, 14 \mathrm{r}, 15 \mathrm{r}, 15 \mathrm{v}, 17 \mathrm{r}, 17 \mathrm{v})$.

${ }^{40}$ AGS, Diversos de Castilla, leg 4, f. 53 y leg 6, f. 14 publicado en LADERO QUESADA, M. A.: "Legislación hacendística de la Corona de Castilla en la Baja Edad Media, Real Academia de la Historia, Madrid 1999, p.337-346.
} 
hacían entrega de los diezmos al tesorero arzobispal, aunque en algunos casos también se detectan resistencias al pago, derivadas posiblemente de la presión fiscal que sufrían aquellas villas en las que los arrendadores y recaudadores reales se encontraban recaudando las alcabalas desde 1480. Es posible que fuese este el motivo que provocó en más de un caso la oposición al pago de los diezmos de la mar al prelado, teniendo en cuenta que fueron las villas de Pontevedra y Cangas, en las que la hacienda arzobispal percibía las alcabalas, las que presentaron mayores dificultades a la recaudación de estos tributos. ${ }^{41}$

Pero en general, la recaudación de los diezmos de la mar durante los años 1481 y 1482 no provocó grandes resistencias entre la población, sobre todo porque los Reyes Católicos no decretaron el embargo de alcabalas, diezmos de la mar y alfolíes hasta 1483, lo que no supuso impedimento para que los recaudadores reales exigieran las alcabalas de los lugares reguengos de la tierra de Santiago desde 1480.

Una vez más, las resistencias al pago de los diezmos de la mar se planteaban en las villas y lugares en las que los recaudadores reales pretendian recudar las alcabalas. En el resto de los puertos de la tierra de Santiago, la recaudación de los diezmos de la mar no planteó problemas y sus habitantes continuaron haciendo entrega de los diezmos de la mar al tesorero arzobispal, tal y como lo habían hecho los años anteriores.

Ahora bien, los que si se vieron afectados ante esta situación de cambio fueron los arrendadores y recaudadores reales que habían arrendado conjuntamente alcabalas, diezmos de la mar y alfolíes, sobre todo a partir de 1483, cuando los reyes decretaron el embargo de las alcabalas, diezmos de la mar y alfolíes de los lugares reguengos. En un albalá de 15 de diciembre de 1486, los reyes exponían a los contadores mayores las peticiones y quejas presentadas por Ruy Martínez de Carballido, arrendador y recaudador mayor de las rentas reales del arzobispado de Santiago y obispado de Tuy durante los años $1480-83 .{ }^{42}$

\footnotetext{
${ }^{41}$ En el caso de la villa de Pontevedra señala el tesorero: "E tiene el dicho Iohan Rodrigues por fenecer su cuenta a cabsa que los vecinos de la dicha villa se levantaron de non querer pagar la dicha media diezma de sal e se ovo de poner entredicho con ellos e aun puesto con los que non quisieron pagar.." (ACS, C1, f.15r). En el puerto de Cangas el tesorero señala lo siguiente: “...e tyene por fenecer su cuenta a cabsa de çiertas personas que non la quisieron pagar la diesma que decían.." (ACS, C1, f.16v) en VÁZQUEZ BERTOMEU, M.: La Hacienda arzobispal.....op cit pp. 165 y 169

42 En él los reyes exponen como el arrendador y recaudador de las alcabalas, diezmos de la mar y alfolies del arzobispado de Santiago de los años 1480-83, Ruy Martínez de Carballido, había sido perjudicado "quexandose que habiendo en él librado todo el cargo del dicho año de 1483 años nos mandamos enbargar las nuestras alcabalas, y diezmos y alfolis de los lugares reguengos que son en el dicho arzobispado de Santiago del dicho año de 1483 en tanto que se veía y determinaba la justicia entre nos y el dicho arzobispo por cuanto él decía pertenecer a su mesa arzobispal y no pertenecer a nos y a nuestra corona real los cuales les estuvieron enbargados fasta este año de 1486..” en AGS, EMR, leg 80, sin foliar.
} 
En relación con las pérdidas ocasionadas en 1480, Carballido señalaba que los agentes arzobispales habían llevado a cabo la embarcación de ciertas mercancías en los puertos de la tierra de Santiago para ir a venderlas al reino de Aragón con la recaudación de los diezmos de la mar pertinentes. ${ }^{43}$ Este fue el motivo fundamental que había impedido a los oficiales reales el embargo de los diezmos de la mar en 1480. El importe resultante de las mercancías descargadas en Valencia había sido recaudado por Juan de Mondragón, criado del arzobispo Fonseca, lo que perjudicaba considerablemente a Carballido, al que se le había hecho cargo del total del importe de las alcabalas, diezmos de la mar y alfolíes de este año.

Como solución, Carballido solicitaba a los reyes la suspensión del importe de los diezmos de la mar correspondiente a las mercancías que se habían vendido en el reino de Aragón en 1480, de acuerdo con el valor que los diezmos habían alcanzado en el arrendamiento de rentas reales llevado a cabo por Luis de Valera en 1482, o bien, conforme al valor de las suspensiones que por los diezmos de la mar se habían aplicado en el cargo de los arrendadores y recaudadores reales de los lugares reguengos en los años de 1484 y 1485. Pedía también que se revocasen todas las libranzas que se habían librado en su cargo, ya que éste año (1480), Carballido no esperaba recaudar ni siquiera la tercera parte de lo que se estimaba recaudar en 1483.

Con respecto al año 1483, Carballido insistía en la dificultad para recaudar las alcabalas, diezmos de la mar y alfolíes de los lugares reguengos como consecuencia del embargo de dichas rentas decretado por los reyes este año. Carballido exigía el descuento de ciertas cuantías de maravedíes de su cargo de 1483, por las pérdidas derivadas de la recaudación de las rentas reales de los lugares reguengos este año.

Los reyes habían mandado resolver esta cuestión a los contadores mayores con los miembros del consejo. Realizadas las pesquisas oportunas, los contadores estimaban en 1.000 florines de oro el importe correspondiente al diezmo de las mercancías vendidas en el reino de Aragón en 1480. Como solución, los reyes exigían al arzobispo Alonso de Fonseca la entrega de dicha cantidad al recaudador de las rentas reales, Ruy Martínez de Carballido. Ahora bien, el prelado se negaba a pagar esta cantidad a Carballido, alegando haber recibido finiquito de los reyes por el que

\footnotetext{
${ }^{43}$ Desde principios de los años ochenta diversos testimonios hacen constar que existía un tráfico de mercancías fluído entre los puertos de la tierra de Santiago y el reino de Valencia que proporcionaba un volumen de ingresos muy notable a la hacienda arzobispal: "Diesma de çierta mercadoría que se descargó en Valençia: Yten que resçeby de Gonzalo de Pas, del diesmo de la nao de su hermano Antón Pas que cargo para Cartagena y Valençia de cierta mercadoría que se descargó en Valençia de que el fue fiel de recabdar el diesmo, 9.540". (ACS, LR C1, fol 17 v) en VÁZQUEZ BERTOMEU, M.: La Hacienda arzobispal... op cit, p. 172.
} 
le había sido condonada toda la deuda relativa a las rentas reales que había tomado en el reino de Galicia desde el último tercio de 1474 hasta fin de $1480 .{ }^{44}$ Ante la respuesta del prelado, Ruy Martínez de Carballido exponía de nuevo a los reyes que los contadores no le habían suspendido en su cargo los 1.000 florines de oro correspondientes al diezmo de las mercancías que habían sido descargadas en el reino de Aragón, como tampoco le había sido suspendida en su cargo la cantidad equivalente a las pérdidas ocasionadas con motivo del embargo de las rentas reales de los lugares reguengos decretado en 1483.

Finalmente, los reyes urgían a sus contadores zanjar las cuentas con Ruy Martínez de Carballido de los años 1480-83, efectuando un cargo y una data, de modo que fuese posible suspenderle en un año lo que en otro hubiese pagado de más. Por otra parte, mandaban a los contadores mayores suspender en el cargo de Carballido de 1483 tantos maravedíes como se habían suspendido en el cargo de los arrendadores y recaudadores mayores de las rentas del arzobispado de los años 1484,1485 y 1486 . El resultado de todo esto fue la suspensión de 2.000 florines de oro a Carballido por los diezmos que había cobrado el arzobispo en 1480 según la estimación de Juan de Alamos y la suspensión al mismo de cierta cuantía de maravedíes por los lugares reguengos de $1483 .{ }^{45}$

No cabe duda de que, el hecho de que los reyes decretaran el embargo de alcabalas, diezmos de la mar y alfolíes en 1483, facilitó la venta de mercancías por parte de los oficiales del arzobispo en los puertos de la Corona de Aragón a principios de los años ochenta, evitando así la pérdida de los diezmos, que generaban beneficios muy considerables para la hacienda arzobispal. ${ }^{46}$ Es posible también que la deci-

44 AGS, EMR, leg 31, f. 134.

45 AGS, EMR, leg 80, sin foliar: Testimonio de Juan de Alamos: "Yo Juan de Alamos so cargo del juramento que vuestras mercedes de mi recivis para el cargo de Ruy Martines de Carvallido que vi la relación de la pesquisa que se hizo en Galicia por Pedro de Cervatos para en el caso de las cosas que se cargaron en los puertos del arzobispado de Santiago y cinco manifiestos firmados de escribano público de los diezmos y que todo ello montaría el diezmo según yo creo a sus altezas pertenescientes seyendo cierto que se cargo lo contenido en la dicha pesquisa y en los dichos manifiestos mucha más cuantía de los mil florines que vuestras mercedes en su cuenta les suspenden y que al tiempo que yo tuve cargo de las rentas de La Coruña y Betanzos en el arzobispado de Santiago vi y supe que se pagaba el diezmo de los pescados y sardinas en el reino de Valencia y se lo den en dinero al tiempo que lo carga el precio como vale cada cosa está a su escoger del dicho arrendador porque ansí es uso y costumbre y para el juramento que fago que esta es la verdad. Alamos." Desconocemos la cuantía exacta que se descontó a Carballido por los reguengos en 1483 debido al mal estado de conservación del documento.

46 Según el testimonio de Juan de Alamos, los beneficios derivados de la venta de mercancías en los puertos de la Corona de Aragón en 1480 habían ascendido a 2.000 florines, equivalentes a 530.000 mrs., una cantidad apreciable teniendo en cuenta que, en 1482, Luis de Valera había arrendado las alcabalas, diezmos de la mar y alfolíes de los lugares reguengos en 532.000 mrs. Véase AGS, EMR, leg 32, f. 56. 
sión de embargar las rentas de los diezmos de la mar en 1483, se hubiera debido a la dificultad que entrañaba el embargo de estas rentas, cuya percepción por parte del prelado compostelano disponía de una base jurídica legal que no existía en el caso de las alcabalas. ${ }^{47}$

El estudio de los libros de recaudación pone de manifiesto que el embargo efectivo de los diezmos de la mar en la tierra de Santiago no tuvo lugar hasta 1483, y de ahí que en los años 1481 y 1482, los oficiales del arzobispo recaudaran el importe correspondiente a los diezmos de la sal y mercancías con total normalidad. Incluso en el caso de los lugares que presentaron ciertas resistencias al pago de las medias diezmas -Cangas y Pontevedra-, los tesoreros arzobispales señalan como dichos lugares hicieron efectiva la entrega de las medias diezmas correspondientes a los años 1481 y 1482 unos años después.

Por último, queda referirnos al elevado volumen de ingresos que, durante estos años, proporcionaban las rentas de los diezmos de la mar. En 1481, se recaudaron un total de $227.368 \mathrm{mrs}$. en concepto de diezmos de la mar, lo que venía a suponer un porcentaje superior al $80 \%$ del total de las rentas reales. Las cuantías devengadas de la recaudación de los juros de heredad que percibe el arzobispo son muy inferiores en comparación con las anteriores. Este año, lo recaudado en concepto de juros de heredad representaba el 17,46\% del total, mientras que las alcabalas de los lugares reguengos aparecen representadas en un $1,50 \%$.

\section{Tabla 5: Diezmos de la mar (1481)}

\section{Localidad/es}

Puerto de Padrón

Villa y puerto de

Pontevedra ${ }^{48}$

Vilanova de Arousa

Villa de Redondela

Villa y puerto de Vigo

Puerto de Cangas ${ }^{49}$

\section{Concepto}

Media diesma de la sal e mercadorías de la mar

Media diesma de la sal y mercadorías de la mar

Media diesma de la sal e mercadorías de la mar Media diesma de la sal y mercadorías de la mar Media diesma de la sal y mercadorías de la mar Media diesma de la sal y mercadorías de la mar
Cuantía

18.822

33.485

4.540

1.450

3.005

9.584

\footnotetext{
${ }^{47}$ Es la concesión de Fernando IV en 1304 de la mitad de las diezmas de la mar al prelado compostelano.

${ }^{48}$ LR, C1, fol 15r en VÁZQUEZ BERTOMEU, M.: La Hacienda arzobispal...op cit, pp. 164-165: "E tiene el dicho Iohan Rodrigues por fenescer su cuenta a cabsa que los vecinos de la dicha villa se levantaron de non querer pagar la dicha media diezma de sal e se ovo de poner entredicho con ellos e aun puesto con los que non quisyeron pagar".

${ }^{49}$ LR, C1, fol 16 v en VÁZQUEZ BERTOMEU, M.: La Hacienda arzobispal...op cit, p. 169: “e tyene por fenesçer su cuenta a cabsa de çiertas personas que non la quisyeron pagar la diesma que devían asy que se me fase cargo de los dichos nueve mill quinientos ...”
} 
Villa y Puerto de Noia

Villa y puerto de Muros

Puerto de Cee

Villa de Fisterra

Villa y puerto de Muxía ${ }^{51}$

Villa de la puebla
Media diesma de la sal y mercadorías de la mar Diesmo de çierta mercadoría que se descargó en Valencia ${ }^{50}$

Media diesma de la sal y mercadorías de la villa de Muros

Media diesma de la sal y mercadorías

Media diesma e mayordomasgo de Finisterra con el coto de Duyo e Sardinero

Media diesma de la sal y mercadorías de la mar y del dicho puerto e el mayordomadgo de la villa

Media diesma de la sal y mercadorías de la mar de la villa y puerto
42.953

9.540

69.106

2.980

7.420

227.368

\section{Total:}

En 1482, la mesa arzobispal compostelana recaudó un total de 331.996 mrs. en concepto de diezmos de la mar, una cantidad ligeramente superior a la recaudada el año anterior por este concepto, una cuantía representaba exactamente el 85,29\% del total de las rentas reales. En menores proporciones se sitúan las cuantías recaudadas por los juros que el arzobispo de Santiago percibía en las villas de Muros, Noya y Padrón $(13,61 \%)$ y las alcabalas de los lugares reguengos de la tierra de Santiago (1\%).

\section{Tabla 6. Diezmos de la mar (1482)}

\section{Localidad/es}

Villa y puerto de Padrón

Villa y puerto de Pontevedra

Vilanova de Arousa

Villa de Redondela ${ }^{52}$

Villa y puerto de Vigo

Villa y puerto de Cangas

Villa y puerto de Noia

\section{Concepto}

Media diesma de la sal y mercadorías de la mar Media diezma de la sal y mercadorías de la mar Media diezma de la sal y mercadorías de la mar. Media diezma de la sal y mercadorías de la mar Media diezma de la sal y mercadorías de la mar Media diesma de la sal y mercadorías de la mar Media diesma de la sal y mercadorías de la mar
Cuantía

13.747

27.115

5.168

651

4.450

8.575

63.396

${ }^{50} \mathrm{LR}, \mathrm{C} 1$, fol 17v en VÁZQUEZ BERTOMEU, M.: La Hacienda arzobispal...op cit, p.172: "Diesma de çierta mercadoría que se descargó en Valençia: Yten que resçeby de Gonçalo de Pas, del diesmo de la nao de su hermano Anton Pas que cargo para Cartagena y Valençia de cierta mercadoría que se descargó en Valençia de que el fue fiel de recabdar el diesmo, 9.540".

${ }^{51} \mathrm{El}$ importe exacto del diezmo de la sal y mercancías de la mar asciende a $1.758 \mathrm{mrs}$. y $2 \mathrm{c}$. El mayordomazgo de la villa rindió este año $1.166 \mathrm{mrs}$.

${ }^{52}$ ACS, LR C1 fol 28 r, en VÁZQUEZ BERTOMEU, M.: La Hacienda arzobispal..., op cit, p.199. 
Villa y puerto de Muros $^{53}$

Puerto de Cee

Villa de Fisterra

Villa y puerto de Muxía Villa de la puebla
Media diesma de la sal y mercadorías de la mar Media diesma de la sal y mercadorías de la mar. Media diezma de la sal y mercaderías de la dicha villa y puerto y mayordomía de la villa con el coto de Duio e Sardiñeiro

Media diezma de la sal y mercaderías de la mar Media diezma de la sal y mercaderías de la mar
168.733

5.500

2.030

32.630

Total:

Por otra parte, hay que tener en cuenta que durante estos años, además de los diezmos de la mar, el arzobispo de Santiago continuó percibiendo ciertos juros de heredad de los que era titular en las medias diezmas de las villas de Muros y Noya. Como veremos a continuación, desde principios de los años ochenta se cuestionó el derecho del prelado a la percepción de dichos juros, aunque en la práctica se le permitiría recaudar el importe correspondiente a los juros de heredad que poseía en las medias diezmas de estas villas mediante tomas efectuadas en dichas rentas.

A partir de 1486, tras el levantamiento del embargo de alcabalas, diezmos y alfolíes de los lugares reguengos por provisión real de 10 de abril de 1486, los habitantes de las villas y puertos de la tierra de Santiago continuaron pagando "las medias diesmas de la sal y mercadorías" al prelado.

El segundo cuaderno de recaudación de la hacienda arzobispal compostelana nos informa acerca de las cuantías recaudadas en concepto de diezmos de la mar durante los años 1487-91 y la proporción que dicha cuantía representa con respecto al resto de las rentas reales. En estos cinco años se recaudaron un total de 2.254.548 mrs. por las rentas de los diezmos de la mar (450.909 mrs/año), una cuantía notablemente superior a la que había sido recaudada los años anteriores. Ahora bien, el porcentaje que representan los diezmos de la mar en estos cinco años se considera muy inferior al que representan los diezmos en los años 1481 y 1482, lo que se explica fundamentalmente como consecuencia del incremento que experimentan las alcabalas de los lugares reguengos, a raíz de su desembargo en 1486. Durante estos años, el valor de las alcabalas sumó un total de

53 ACS LR C1, fol. 30 r en VÁZQUEZ BERTOMEU, M.: La Hacienda arzobispal...., op cit, p.204: "E dio por cuenta que rentó la dicha media diezma de las mercadorías de la mar çiento y çinquenta y tres maravedís de pares de blancas. E más que rentó la media diezma de la sal de la dicha villa de Muros el dicho año de que fue fiel el dicho Juan Garçía segund dio por cuenta, dies y ocho moyos de sal; de los quales dio vendidos los dies moyos a dos mill maravedis pares de blancas cada moyo, que son asy veyente mill maravedís de pares de blancas en los dichos dies moyos e los otros ocho moyos restantes quedaron en su poder del dicho Juan Garçi, e los queda deviendo en sal, porque dixo que non los pudo vender porque venieron tarde" 
3.666.347 mrs., lo que venía a suponer exactamente el 59,26\% del total de lo recaudado por las rentas reales. En segundo lugar se presentan las rentas de los diezmos de la mar que en este período suponen algo más del 35\% del total, y en tercer y último lugar, los juros de heredad que el prelado compostelano posee situados en ciertas villas y lugares de la tierra de Santiago, que aparecen representados en proporciones del 4,28\%.

Tabla 7: Diezmos de la mar (1487-91)

$\begin{array}{llll}\text { Localidad/es } & \text { Concepto } & \text { Cuantía. } & \text { Mrs/año } \\ \text { Villa de Padrón } & \text { Media diezma de la sal de la mar } & 152.314 & 30.462 \\ \text { Vilanova de Arousa } & \text { Media diezma de la mar } & 157.952 & 31.590 \\ \text { Villa de Pontevedra } & \text { Media diezma de la mar, de la sal e } & 474.060 & 94.812 \\ & \text { mercadorías } & & \\ \text { Villa de Redondela } & \text { Media diezma } & 28.409 & 5.681 \\ \text { Villa de Vigo } & \text { Media diezma de la sal e mercadorías } & 73.682 & 14.736 \\ \text { Cangas } & \text { Media diezma de la sal e mercadorías } & 146.828 & 29.365 \\ \text { Villa de la Puebla } & \text { Media diezma de la sal e mercadorías } & 241.509 & 48.301 \\ \text { Villa de Noia } & \text { Media diezma de la sal e mercadorías } & 292.174 & 58.434 \\ \text { Villa y puerto de Muros } & \text { Media diezma de la sal e mercadorías } & 573.518 & 114.703 \\ \text { Puerto de Cee } & \text { Media diezma de la sal de la mar } & 14.414 & 2.882 \\ \text { Villa de Fisterra } & \text { Diezma de la sal e mercaderías del dicho } & 77.000 & 15.400 \\ & \text { puerto e el maiordomadgo de la dicha } & & \\ \text { Villa de Muxía } & \text { villa con los cotos de Duyo e Sardinero } & & \\ \text { Villa de Malpica } & \text { Media diezma de la sal e mercadorías } & 12.394 & 2.478 \\ & \text { Media diezma de la sal } & 10.284 & 2.056\end{array}$

Total:

2.254.548 $\quad 450.909$

\section{JUROS DE HEREDAD Y MERCEDES DE POR VIDA.}

Una partida más de los ingresos de la mesa arzobispal compostelana son los juros y mercedes que percibe por merced regia en las rentas reales de la tierra de Santiago.

\footnotetext{
${ }^{54}$ Durante los años 1487-91, los diezmos de la mar de la villa de Finisterre se recaudan junto a otros derechos como los que derivan de la explotación del patrimonio y ejercicio de la jurisdicción que se pagan en cada una de las unidades de explotación agraria -mayordomías y casales-. Considerando que la recaudación de los diezmos de la mar en los puertos de la tierra de Santiago proporciona niveles de ingresos muy notables a la hacienda arzobispal, mayores incluso que los que se derivan de la recaudación de tributos de carácter señorial en el marco de las mayordomías, decidimos incluir lo recaudado en la villa de Finisterre en la partida de ingresos relativa a los diezmos de la mar.
} 
El registro de bienes de 1435 y los libros de recaudación de la hacienda arzobispal se refieren a un juro de heredad de 4.000 mrs. situados en las rentas del alfolí de la sal de Padrón. En este caso, el privilegio no sólo recaía en la figura del arzobispo, sino que Juan II lo había otorgado por merced al arzobispo, deán y cabildo de la iglesia de Santiago a partir del trueque efectuado con el adelantado Pedro Afán de Ribera, miembro del linaje de Huéjar, en el aljarafe sevillano. ${ }^{55}$ A principios de los años ochenta, los agentes arzobispales se encontraron con serias dificultades para recaudar este juro. Concretamente en los años 1481 y 1482, el arrendador y recaudador real, Ruy Martínez de Carballido, se negaba a pagar los 4.000 mrs. de juro a los recaudadores de la hacienda arzobispal si no mostraban el privilegio que reconocía al arzobispo y cabildo el derecho a la percepción de dicho juro. Durante estos años, los arrendadores y recaudadores reales recorrieron la tierra de Santiago exigiendo a los habitantes de los denominados lugares reguengos la entrega de alcabalas y otras rentas reales que hasta el momento habían pagado a la hacienda arzobispal. No sabemos si, en efecto, los agentes arzobispales mostraron a los arrendadores reales el privilegio que reconocía el derecho del arzobispo, deán y cabildo a la percepción de este juro, pero lo cierto es que, finalmente, los agentes arzobispales consiguieron recaudar el importe correspondiente al juro del trueque de Pedro Afán. A partir de 1486, una vez levantado el embargo de las alcabalas, diezmos de la mar y alfolíes en la tierra de Santiago, la recaudación de este juro se llevaba a cabo con total normalidad. ${ }^{56}$

Por otra parte, los libros de recaudación de la hacienda arzobispal registran la titularidad de $2.000 \mathrm{mrs}$. de juro de heredad situados en las alcabalas del vino de la ciudad de Santiago a favor del prelado compostelano. Por privilegio de Juan II otorgado el 6 de noviembre de 1431, el arzobispo de Santiago recibía 2.000 mrs. de juro de heredad a partir de la permuta efectuada con el mariscal Pedro García de Herrera por el lugar de Arrayaces, situado cerca de Ampudia, que hasta el momento había pertenecido a la mesa arzobispal compostelana. A su vez, el mariscal había obtenido estos 2.000 mrs. por renunciación y traspaso que el conde de Castro, su hermano, había efectuado en su favor, de los $4.800 \mathrm{mrs}$. y 4 c. que tenía situados en las alcabalas de los barrios de Balvas, de los que el rey le había hecho merced el 14 de octubre de $1430 .{ }^{57}$ En 1481, el tesorero arzobispal, Francisco de Treviño, recaudaba estos $2.000 \mathrm{mrs}$. en las alcabalas del vino de la ciudad de Santiago. Sin embargo, el año

${ }^{55}$ AGS, CMC, $1^{\text {a }}$ época, leg 71, sin foliar: Privilegio otorgado en Medina del Campo, 15 de Febrero de 1418.

${ }^{56}$ RODRÍGUEZ GONZÁLEZ, A.: O tumbo vermello de don Lope de Mendoza, Santiago de Compostela, 1995, f. 88 v, pp 130-131 y ACS, LR C1 f. 13 r, 25 r, 25 v y LR C2 f. 10 r en VÁZQUEZ BERTOMEU, M.: “La Hacienda arzobispal...”op cit pp. 160, 191 y 251.

${ }^{57}$ AGS, EMR, Mercedes y privilegios, leg 4-II, f. 107. 
siguiente, el arrendador de las rentas de la hacienda arzobispal, no hizo entrega del importe correspondiente a este juro, lo que sin duda hay que poner en relación con la aparición de los oficiales reales en la tierra de Santiago dificultando la recaudación de juros y alcabalas. Desde mediados de los años ochenta, los libros de recaudación registran el pago de esta cantidad al tesorero arzobispal Nicolás de Acevedo. Los Reyes Católicos confirmaron este privilegio del que tenemos constancia durante todo el reinado y en los primeros años del siglo XVI, aunque ignoramos la fecha en la que tuvo lugar tal confirmación. ${ }^{58}$

El arzobispo de Santiago y su mesa arzobispal eran titulares de un juro de 12.000 mrs. situados sobre las alcabalas de las fieldades de dichas villas. Al igual que sucede con los juros ya mencionados, los libros de recaudación de la hacienda arzobispal constatan que durante los años 1481 y 1482, los oficiales de la monarquía dificultaron su recaudación a los fieles del arzobispo. ${ }^{59}$ Sin embargo, desde 1487 en adelante, la hacienda arzobispal compostelana va a percibir estos 12.000 mrs. de juro con total normalidad. ${ }^{60}$

Así, desde mediados de los años ochenta, los agentes arzobispales aparecen recaudando las alcabalas de las fieldades de Muros y Noya mediante tomas realizadas en dichas rentas. Un estudio detallado de la documentación hecendística pone de manifiesto que, posiblemente, los 12.000 mrs. de juro que estaban situados sobre las alcabalas de las fieldades de las villas de Noya y Muros, no disponían de la base jurídica necesaria para proceder a su cobro. Sin embargo, todo parece indicar que los reyes debieron autorizar al prelado la recaudación de dicho juro, como una manera de premiar su fidelidad a la monarquía y las continuas prestaciones económicas con las que el prelado había contribuido a sufragar los gastos de la Corona en momentos decisivos. ${ }^{61}$

El prelado compostelano disfrutaba también de importantes juros de heredad situados sobre las rentas de las medias diezmas pertenecientes al monarca en los puertos de la tierra de Santiago. Concretamente el arzobispo percibía 35.000 mrs. situados por mitad en las medias diezmas de la parte real de los puertos de Muros y Noya.

\footnotetext{
${ }^{58}$ AGS, CMC, $1^{\text {a }}$ época, leg 71, sin foliar. También RODRÍGUEZ GONZÁLEZ, A.: O tumbo vermello....op cit, f. 85 v, p. 127 y ACS, LR C1, f. 10 r, 22 r y LR C2 f. 6r, en VÁZQUEZ BERTOMEU, M.: La Hacienda arzobispal...op cit, pp.151, 182 y 240.

${ }^{59}$ ACS, LR C1, fols 17r, 17v, 18r, 29v y 30r en VÁZQUEZ BERTOMEU, M.: La Hacienda arzobispal...op cit, pp. 171-174, 203 y 205.

${ }^{60}$ ACS, LR C2, fols 15r y 16r en VÁZQUEZ BERTOMEU, M.: La Hacienda arzobispal...op cit, pp. 264-266

${ }^{61}$ AGS, CMC, $1^{\text {a }}$ época, leg 71, sin foliar y Expedientes de Hacienda, leg 11, sin foliar.: La documentación de años posteriores, especialmente la que se refiere a los años 1492-1504 señala la percepción de estos juros por parte del arzobispo mediante tomas efectuadas en las rentas. Las relaciones del situado de estos años señalan que el arzobispo toma estos juros de las rentas de Muros y Noya sin mostrar privilegio.
} 
El origen de los 35.000 mrs. de juro de heredad que se sitúan en las medias diezmas pertenecientes al monarca se encuentra en la concesión de un antiguo privilegio de Fernando IV a la Iglesia Compostelana. Efectivamente, en 1304, Fernando IV otorgaba al arzobispo don Rodrigo y a sus sucesores la mitad de los diezmos de la mar que se pagaban en los puertos de la tierra de Santiago. ${ }^{62}$

Por esta merced, el arzobispo pasaba a percibir la mitad de los diezmos que pertenecían al monarca cobraba en los puertos de la tierra de Santiago, concretamente en los puertos de Vigo, Redondela, San Paio de Lodo, Pontevedra, Padrón, Noya y Muros. Es posible que, durante estos años el monarca hubiera concedido al prelado compostelano 10.000 mrs. de juro heredad en la mitad de los diezmos que habian quedado para la corona, pues el tumbo vermella de 1435 se refiere a la percepción de esta cantidad en la mitad de los diezmos pertenecientes a la parte real. Esta concesión se completaba en 1310 a este juro y al añadir a la mitad de los diezmos de los que ya gozaba el prelado, otros $10.000 \mathrm{mrs}$. de juro de heredad a percibir sobre la parte de los diezmos que había quedado para la Corona. El 20 de febrero de 1310, Fernando IV donaba al arzobispo don Rodrigo y a sus sucesores, $10.000 \mathrm{mrs}$. de juro de heredad situados sobre la mitad de los diezmos pertenecientes a la Corona en los puertos del señorío de la Iglesia de Santiago. ${ }^{63}$

El tumbo vermello de 1435 nos indica la pertenencia al arzobispo de 10.000 mrs. de la moneda vieja situados en la mitad de los diezmos pertenecientes al monarca en las villas y lugares de la tierra de Santiago por los que el arzobispo percibiría $25.000 \mathrm{mrs}$. (cinco blancas/ mrv.) y otros $10.000 \mathrm{mrs}$. de juro de la moneda usual, sumando un total de $35.000 \mathrm{mrs}$.:

"Otrosi tenedes del rey nuestro señor, por merçed de juro de heredad en cada un año en la otra su meytad de los dichos diesmos de las villas e logares del dicho vuestro arçobispado e señorio dies mill maravedis de buena moneda vieja e otros dies mill de la moneda usual por los quales dichos dies mill maravedis de buena moneda estades en posison de levar çinquo blancas por maravedi que montan ellos al dicho respecto veyente e çinquo mill maravedis .levades agora de la moneda que corre, que dos blancas fazen un maravedi, que son todos treyenta e çinquo mill maravedis de la dicha moneda blanca...XXXV mill maravedís. E destos dichos maravedís fazedes toma de cada año. E los dichos diezmos de la parte del dicho señor rey por vertud de los previllejos que vos e la dicha vuestra igllesia tenedes sobre ello". 64

${ }^{62}$ GONZÁlEZ BALASCH, M. T.: El Tumbo B de la catedral...op cit, docs. 108 y 159, pp. 227 y 321). Véase también GONZÁLEZ VÁZQUEZ, M.: El arzobispo de Santiago... op cit, p. 318.

${ }^{63}$ GONZÁlEZ BALASCH, M. T.: El Tumbo B de la catedral...op cit, doc. 118, p. 256, y GONZÁLEZ VÁZQUEZ, M.: El arzobispo de Santiago... op cit, pp 321-322.

${ }^{64}$ RODRÍGUEZ GONZÁLEZ, A.: O tumbo vermello....op cit, f. 101 r, p. 146. 
La documentación de la Contaduría Mayor de Cuentas relativa al reinado de los Reyes Católicos registra un total de 35.000 mrs. de juro de heredad a percibir por la mesa arzobispal compostelana. De estos 35.000 mrs., 25.000 mrs. corresponderían a los 10.000 mrs. de moneda vieja que Fernando IV había concedido en 1310 al arzobispo de Santiago y aparecen situados sobre la mitad de los diezmos de la tierra de Santiago pertenecientes a la Corona. El resto, $10.000 \mathrm{mrs}$. corresponderían a la primera cesión efectuada por el mismo monarca en fecha indeterminada, y, del mismo modo, se sitúan en las medias diezmas de los puertos del señorío de Santiago pertenecientes a la Corona.

Desde principios del siglo XV, el prelado compostelano percibía el juro en su totalidad, $35.000 \mathrm{mrs}$, en la mitad de los diezmos de la mar perteneciente a la Corona en los puertos de la tierra de Santiago, y del mismo modo, durante el reinado de los Reyes Católicos, tenemos constancia de la percepción por parte del arzobispo de estos $35.000 \mathrm{mrs}$. de juro heredad situados por mitad en las rentas de los diezmos de la mar pertenecientes a la Hacienda Regia en los puertos de Muros y Noya.

Una vez más, la recaudación de este juro no resultó fácil, sobre todo porque contaba con la resistencia de los arrendadores y recaudadores reales que se negaban a que los fieles del arzobispo recaudasen una cantidad tan notable, a la que se añadía la mitad de los ingresos que generaban los diezmos de la mar de la tierra de Santiago, pertenecientes a la hacienda arzobispal compostelana en virtud del privilegio otorgado por Fernando IV en 1304.

Las cuentas del tesorero arzobispal, Francisco de Treviño, relativas al año 1481 ponen de manifiesto que los fieles del arzobispo no habían logrado recaudar los 17.500 mrs. situados en las medias diezmas de la mar del puerto de Noya con motivo de las extorsiones que Ruy Martínez de Carballido, arrendador y recaudador mayor de las rentas reales había causado a los agentes arzobispales dificultándoles la recaudación. El arrendador Carballido, negaba el derecho de la hacienda arzobispal a la percepción de éste y otros juros. La tensión entre el arrendador y recaudador real y los recaudadores o fieles arzobispales había llegado a tal punto que Carballido había solicitado a los reyes una carta para hacer ejecución en los bienes del tesorero arzobispal, Francisco de Treviño, a causa del embargo que éste había realizado en las de las medias diezmas de Noya y Muros y en los alfolíes de la sal de Padrón. ${ }^{65}$

${ }^{65}$ ACS, LR C1, fols 17r y 17v en VÁZQUEZ BERTOMEU, M.: La Hacienda arzobispal...op cit, pp 171-172. 
Idéntica fué la situación que se dió con respecto al pago de las rentas de las medias diezmas de la villa de Muros al arzobispo. ${ }^{66}$ En 1481 no se exigió a los tesoreros arzobispales la entrega de los $17.500 \mathrm{mrs}$. de juro de heredad situados sobre las medias diezmas del puerto de Muros porque los fieles encargados de su cobro no habían sido capaces de recaudar dichas rentas.

El año siguiente, 1482, el tesorero arzobispal tampoco había logrado recaudar los juros situados en las medias diezmas de Muros y Noya a causa del embargo que Carballido había hecho de las mismas. ${ }^{67}$ Sin embargo, en los años posteriores los reyes debieron autorizar al prelado el cobro de dichos juros, tal y como se pone de manifiesto en los cuadernos de recaudación. ${ }^{68}$

A mediados de los años ochenta, la situación parece cambiar. Las cuentas del tesorero arzobispal, Nicolás de Acevedo, revelan que a partir del año 1487, el pago de juros situados sobre las medias diezmas de la mar de Muros y Noya a los tesoreros arzobispales se efectuó con total normalidad. ${ }^{69}$ Desde 1487 en adelante, el arzobispo y su mesa arzobispal pasaban a percibir por entero éstos $35.000 \mathrm{mrs}$. en la mitad de los diezmos de la tierra de Santiago pertenecientes a la Corona. La percepción de dicho juro se lleva a cabo mediante las "tomas" correspondientes que el arzobispo realiza en los diezmos de la mar de los puertos de Muros y Noya. Habría que preguntarse porqué durante todo el siglo XV el arzobispo de Santiago y su mesa arzobispal procedieron a recaudar de estos $35.000 \mathrm{mrs}$. de juro de heredad mediante tomas efectuadas en las rentas de Muros y Noya. ${ }^{70}$ Es posible que los privilegios concedidos por Fernando IV no hubiesen sido confirmados por los monarcas posteriores y que, como consecuencia de ello, la base jurídica que respaldaba dichos privilegios hubiese quedado cuestionada. ${ }^{71}$

Al parecer, éste no era el único caso que se planteaba acerca de la percepción de ciertos juros de heredad y mercedes de por vida. Tras la publicación de las

\footnotetext{
${ }^{66}$ ACS, LR C1, fol 18r en VÁZQUEZ BERTOMEU, M.: La Hacienda arzobispal...op cit, pp. 173-174.

${ }^{67}$ ACS, LR C1, fols 29v y 30r, en VÁZQUEZ BERTOMEU, M.: La Hacienda arzobispal...op cit, pp. 203-205.

${ }^{68}$ En cada una de las partidas correspondientes a los juros mencionados aparece una nota del tesorero arzobispal que indica que posteriormente dichos juros fueron pagados.

${ }^{69}$ ACS, LR C2, fols 15r y 16r en VÁZQUEZ BERTOMEU, M.: La Hacienda arzobispal....op cit, pp. 264-266.

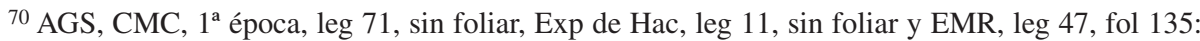
Existen relaciones de situado muy completas para los años 1481, 1482, 1488, 1492, 1493, 1494, 1495, $1496,1497,1502,1503$ y 1504.

${ }^{71}$ AGS, CMC, $1^{\text {a }}$ época, leg 71, sin foliar: Una relación de situado de 1495 nos indica que en 1355 había sido confirmado el privilegio que reconocía al arzobispo su derecho al cobro de $10.000 \mathrm{mrs}$. de juro anuales en la mitad de los diezmos pertenecientes a la Corona Real.
} 
cartas declaratorias de Toledo en 1480, los reyes pretendían reducir los juros y mercedes concedidos por el rey Enrique IV a la nobleza gallega de manera inoportuna con posterioridad al año $1464 \mathrm{y}$, al mismo tiempo, anular aquellos que carecieran de una base jurídica reconocida.

A principios de los años ochenta, al tiempo que se debatía el derecho del arzobispo a la percepción de alcabalas, diezmos de la mar y alfolíes de los lugares reguengos, se planteaba el tema de los juros que la hacienda arzobispal percibía en las rentas reales de la tierra de Santiago. De este modo, no sólo se cuestionaba el derecho del arzobispo a la percepción de aquellos juros sobre los que no mostrase la carta de privilegio que les validaba, sino también de aquellos otros que contaban con una sólida base jurídica. Durante estos años fueron revisados los 35.000 mrs. de juro de heredad que el arzobispo y su mesa arzobispal percibían por mitad en las rentas de los diezmos de la mar de Muros y Noya, los 12.000 mrs. de juro de heredad que poseía situados sobre las alcabalas de las fieldades de Muros y Noya, los 4.000 mrs. de juro situados en las rentas del alfolí de la sal de Padrón que el prelado había obtenido a partir del trueque efectuado con el adelantado Pedro Afán de Ribera y los 2.000 mrs. que poseía situados en las alcabalas del vino de Santiago, obtenidos a partir de la permuta efectuada con el mariscal Pedro García de Herrera por el lugar de Arrayaces.

La solución al problema de los juros que el prelado compostelano percibía en las rentas reales de la tierra de Santiago tendría lugar a mediados de los años ochenta. En 1486, al tiempo que los reyes levantan el embargo de las alcabalas, diezmos de la mar y alfolíes de la sal de los lugares reguengos de la tierra de Santiago, autorizaban al arzobispo la recaudación de los juros situados en las rentas reales ordinarias de la tierra de Santiago. Los reyes tomaban esta decisión sin tener en cuenta la calidad de los juros o las condiciones en que dichos juros habían sido obtenidos. Indudablemente, los Reyes Católicos tuvieron en cuenta otros factores a la hora de autorizar al prelado la percepción de estos juros, sobre todo porque, durante estos años, Alonso de Fonseca se habra convertido en uno de los principales puntales financieros del reino.

En la guerra civil castellana, Alonso de Fonseca había demostrado su apoyo incondicional a la Corona defendiendo la causa de la reina Isabel. Éste era el motivo que los reyes exponían cuando tomaron la decisión de levantar el embargo de las alcabalas, diezmos de la mar y alfolíes de los lugares reguengos. ${ }^{72}$ Del mismo modo, Alonso de Fonseca había contribuido a sufragar la guerra de Granada prestando

72 El levantamiento del embargo de alcabalas, diezmos de la mar y alfolíes de los lugares reguengos tuvo lugar por provisión real el 10 de abril de 1486 en FERNÁNDEZ CORTIZO, C.: "Las alcabalas enajenadas..." op cit, p.136. También véase AGS, RGS, 23 de septiembre de 1485, fols 2 y 3 . 
7.000.000 de maravedíes., lo que le había redituado una merced de 300.000 mrs. de por vida a partir de 1498 en adelante. ${ }^{73}$ Unos años después, el prelado compostelano contribuía de nuevo a costear el pago de tropas de las guerras de Nápoles.

La fidelidad del arzobispo Fonseca a la monarquía de los Reyes Católicos le había convertido en uno de los personajes de mayor influencia política del reino. Buena prueba de ello había sido su nombramiento como presidente de la audiencia del reino de Galicia en 1480. En el plano económico, su apoyo incondicional a la monarquía de los Reyes Católicos le había procurado beneficios muy considerables. En 1486, recuperaba las alcabalas, diezmos de la mar y alfolíes de los lugares reguengos de la tierra de Santiago y el derecho a percibir ciertos juros de heredad situados sobre las rentas reales, incluyendo aquellos cuya base jurídica no estaba suficientemente clara. ${ }^{74}$

A finales de los años noventa, el prelado compostelano obtenía $300.000 \mathrm{mrs}$. de merced de por vida en compensación a su contribución económica en la guerra de Granada. Estos 300.000 mrs. para consumir en vida del prelado se situaban en las alcabalas, diezmos y alfolíes de la tierra de Santiago con la siguiente distribución: en las alcabalas, medias diezmas y alfolí de Finisterre 90.000 mrs., Cee 64.000, y Malpica 40.000, en las alcabalas y alfolí de Villanueva de Arosa 80.000 mrs. y en las alcabalas de Puebla del Caramiñal 26.000 mrs. ${ }^{75}$ Con esta cuantía de maravedíes de por vida, los reyes trataban de amortizar la deuda contraída con el prelado por los préstamos con los que había contribuído en la guerra de Granada. ${ }^{76}$ Concretamente estos $300.000 \mathrm{mrs}$. de por vida se otorgaron al arzobispo en pago y devolución de los 7.000.000 de maravedíes que había prestado a la monarquía en 1491.

\footnotetext{
${ }^{73}$ AGS, CMC, 1 a época, leg 71, sin foliar.

${ }^{74}$ Sobre el gobierno y administración del arzobispado de Santiago en tiempos de Alonso II de Fonseca véase VÁZQUEZ BERTOMEU, M.: "El arzobispo don Alonso de Fonseca. Notas para su estudio" en Cuadernos de Estudios Gallegos, Tomo XLVII, Fascículo 112, Santiago, 2000 y PARDO DE GUEVARA Y VALDÉS, E.: "El arzobispado de Santiago en tiempos de don Alonso II de Fonseca" en Hispania Sacra, v. XXX (1977), pp. 183-200

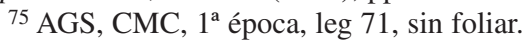

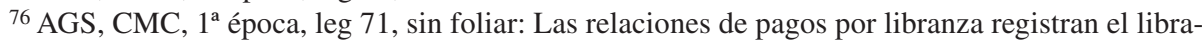
miento de 1.000 .000 de maravedíes al arzobispo Fonseca el año 1497 como pago y compensación de los 7.000.000 de maravedíes con los que había contribuído a costear la guerra de Granada. Desde 1498 en adelante, se libraron al arzobispo Fonseca 300.000 mrs. de merced de por vida por la misma causa y en 1499 estos 300.000 mrs. quedaban situados en las rentas del arzobispado de Santiago. En 1500 tenemos noticia del libramiento al arzobispo Fonseca de éstos $300.000 \mathrm{mrs}$. de merced de por vida que se le habían mandado librar en 1498. Véase mi tesis doctoral Hacienda y gobierno de los Reyes Católicos en Galicia, tesis doctoral inédita, Madrid, Universidad Complutense, 2007, pp. 819 y 1011 .
} 
No era la primera vez que el arzobispo de Compostela había actuado como prestamista al servicio de la monarquía para costear la guerra de Granada. En 1488, había prestado 5.000.000 de maravedíes para este mismo fin, aunque dicha cantidad había sido devuelta a Fonseca íntegramente el año siguiente. Del mismo modo, en 1489, el arzobispo había vuelto a prestar ciertas cuantías de maravedíes a los monarcas para la guerra de Granada. ${ }^{77}$ Es posible que, en 1491, el arzobispo Alonso de Fonseca hubiese recuperado la práctica totalidad de las cantidades que había prestado a la Corona en 1489, aunque todavía este año se debían a Fonseca 1.600.000 mrs. por este concepto. ${ }^{78}$

\section{CONCLUSIONES}

En los últimos decenios del siglo XV, la hacienda arzobispal compostelana contaba con cuatro fuentes principales de ingresos. En primer lugar, el arzobispo y su mesa arzobispal percibían una buena parte del volumen de sus ingresos derivados de la explotación del patrimonio y del ejercicio de la jurisdicción en la tierra de Santiago. ${ }^{79}$ Entre estos ingresos se cuentan los procedentes de mayordomías y casales que resultan del arrendamiento de unidades agrarias a particulares. Junto a éstos ingresos se distinguen otros como los que derivan de la gestión de bienes inmuebles -ciertas casas y huertas en la ciudad de Santiago-, del ejercicio de la justicia -chancillerías de las alcaldías de Noya y Muros- etc... Pero sin duda, la principal fuente de ingresos que deriva del ejercicio de la jurisdicción de la iglesia compostelana en la tierra de Santiago es el servicio que el arzobispo recauda en la ciudad de Santiago y en los lugares reguengos de la tierra de Santiago. ${ }^{80}$ Una segunda fuente de ingresos es la que procede de la percepción de rentas reales: alcabalas,

\footnotetext{
77 AGS, EMR, leg 97, fol 10 en LADERO QUESADA, M. A.: La Hacienda real de Castilla en el siglo $X V$, La Laguna, 1976, p.322: La documentación no precisa cual fue la cuantía que el arzobispo de Santiago había prestado este año a la monarquía.

${ }^{78}$ Sobre los préstamos del arzobispo Fonseca para la guerra de Granada véase AGS, EMR, leg 45, fol 34 y leg 97, fols 4 y 10 en LADERO QUESADA, M. A.: La Hacienda real de Castilla ...op cit, pp.319-324.

79 VÁZQUEZ BERTOMEU, M.: La Hacienda arzobispal... op cit, pp. 37-38. Esta autora considera el servicio que el arzobispo recauda en la tierra de Santiago como uno más de los impuestos reales que el arzobispo recauda en la tierra de Santiago. En mi opinión, se trata de un impuesto de origen real que desde principios del siglo XV aparece convertido en un tributo de carácter señorial y de ahí, que nosotros hayamos considerado incluirlo en la nómina de ingresos que derivan del ejercicio de la jurisdicción de la iglesia compostelana en la tierra de Santiago.

${ }^{80}$ Para el estudio de estas cuestiones seguimos fielmente la obra de VÁZQUEZ BERTOMEU, M.: La Hacienda arzobispal...op cit, pp.25-53.
} 
diezmos de la mar y ciertos juros de heredad situados sobre las rentas reales de la ciudad de Santiago y su tierra. La tercera la constituyen las rentas eclesiásticas, que a juzgar por los libros de recaudación fonsecanos, presentan unos porcentajes muy modestos, lo que se explica, en cierto modo, porque parte de las rentas eclesiásticas procedentes de beneficios, a fines del siglo $\mathrm{XV}$, habían quedado integradas en el marco de las mayordomías. Por último, un cuarto grupo incluye ingresos procedentes de la audiencia arzobispal, la venta de oficios, la participación en el ancoraje coruñés o las ganancias de las tiendas compostelanas de concheiros.

Una vez estudiados cada uno de los impuestos reales que percibe el arzobispo y su mesa arzobispal en la tierra de Santiago resulta conveniente tratar de precisar la importancia que dichas rentas poseen con respecto al volumen global de los ingresos, a fin de poder valorar la importancia relativa que, en términos económicos, presentan unos ingresos con respecto a otros. Pero además, cabe hacer un análisis comparativo acerca de las propias rentas reales para conocer cuales eran las que generaban mayor volumen de ingresos y como el importe resultante de la recaudación de cada una de estas rentas varió en función de las circunstancias de cada momento.

El análisis porcentual del total de los ingresos que recauda la hacienda arzobispal compostelana pone de manifiesto que, en 1481, el mayor volumen de ingresos procede de la gestión y administración del patrimonio y del ejercicio de la jurisdicción de la iglesia en el señorío de la tierra de Santiago. Este año, las cuantías de maravedíes recaudadas por este concepto sumaron 432.130 mrs., lo que venía a suponer exactamente el $54,16 \%$ del total de los ingresos, con la siguiente distribución: servicios $(24,78 \%)$, mayordomías $(24,47 \%)$, inmuebles $(3,77 \%)$ y chancillerías $(1,14 \%)$. Vemos, por tanto, que los niveles de rentas que se generan en el ámbito de las mayordomías se aproximan bastante a aquellos que derivan de la recaudación del servicio en la tierra de Santiago. Ahora bien, conviene tener en cuenta que los ingresos derivados de la recaudación del servicio serían algo superiores a los que aquí se exponen, sobre todo porque este año y el siguiente (1482), el arzobispo de Santiago había renunciado a la recaudación del servicio en aquellos lugares en los que dicho tributo se arrendaba junto a los derechos de alcabalas. El volumen de ingresos recaudado en el marco de las mayordomías es también muy notable. En cada una de estas circunscripciones administrativas, el arzobispo no sólo recaudaba ingresos de carácter agrario y señorial sino también aquellos que tenían que ver con el ejercicio de la jurisdicción.

El importe resultante de la recaudación de las rentas reales ascendía este año a $280.598 \mathrm{mrs}$. de un total de $797.552 \mathrm{mrs}$. en que se estima el volumen global de ingresos de la mesa arzobispal compostelana. Los ingresos procedentes de la per- 
cepción de rentas reales suponían el 35,17\% del total, distribuídos en las siguientes proporciones: diezmos de la mar $(28,50 \%)$, juros de heredad $(6,14 \%)$ y alcabalas $(0,53 \%)$. El porcentaje de las rentas reales es también considerable, aunque sería algo superior si se tuvieran en cuenta las alcabalas de los lugares reguengos que este año no se pagaron a la mesa arzobispal compostelana.

En tercer y último lugar se sitúan las rentas eclesiásticas, cuyos niveles de ingresos son también considerables, 11,30\% del total, si bien hay que tener en cuenta que muchas de las rentas procedentes de beneficios eclesiásticos, a fines del siglo $\mathrm{XV}$, habían quedado integradas en el marco de las mayordomías.

Al igual que el año anterior, en 1482, los ingresos derivados de la administración del patrimonio y ejercicio de la jurisdicción se sitúan en primer lugar. Este año, las rentas devengadas por estos conceptos sumaron un total de $420.590 \mathrm{mrs}$. de un total de $900.981 \mathrm{mrs}$. estimados para el conjunto de ingresos de la mesa arzobispal. Las rentas procedentes de la gestión de los bienes patrimoniales y ejercicio de la jurisdicción representan el 46,65\% del total de los ingresos con el siguiente reparto porcentual: mayordomías $(21,31 \%)$, servicios $(20,81 \%)$, bienes inmuebles $(3,43 \%)$ y chancillerías de las alcaldías $(1,10 \%)$. En segundo lugar se sitúan las rentas reales que representan este año el 43,18\% del total: diezmos de la mar $(36,84 \%)$, juros de heredad $(5,88 \%)$ y alcabalas $(0,46 \%)$. Y, por último, las rentas eclesiásticas son las que alcanzan las menores proporciones con un 9,24\% del total de los ingresos.

Desde mediados de los años ochenta las proporciones se invierten, de manera que son las rentas reales las que pasan a ocupar el primer lugar. Efectivamente, durante los años 1487-91, el valor de las rentas reales alcanzó los 6.185.895 mrs., una cuantía muy superior a los 3.049.575 mrs. que importaron en estos años las rentas derivadas de la explotación del patrimonio territorial y del ejercicio de la jurisdicción. Por consiguiente, son las rentas reales -alcabalas, diezmos de la mar y juros de heredad- las que pasan a ocupar el primer lugar en cada uno de estos años, representando unos niveles de ingresos superiores al 50\% del total. En este período (1487-91), las rentas reales representaron exactamente el 53,5\% del total de los ingresos de la mesa arzobispal compostelana: alcabalas de los lugares reguengos $(31,71 \%)$, diezmos de la mar $(19,50 \%)$ y juros de heredad $(2,29 \%)$. El notable incremento que experimentan las rentas reales en este período se debe fundamentalmente al desembargo de las alcabalas de los lugares reguengos y su concesión con carácter vitalicio al arzobispo de Santiago, Alonso de Fonseca.

En segundo lugar se sitúan las rentas que la mesa arzobispal compostelana obtiene de la explotación del patrimonio territorial y del ejercicio de la jurisdicción en la tierra de Santiago. Por esta vía, el arzobispo y su mesa arzobispal obtienen 
notables beneficios, unos 3.049.575 mrs. en estos cinco años (1487-91), lo que venía a suponer el 26,36\% del volumen global de los ingresos. Esta segunda fuente de ingresos proporciona tributos de carácter agrario y señorial como los que proceden de la explotación de las mayordomías $(9,98 \%)$, servicios $(10,10 \%)$, alcaldías de las chancillerías $(4,53 \%)$ y bienes inmuebles $(1,75 \%)$.

En tercer lugar se sitúan las rentas eclesiásticas, que en estos cinco años sumaron 1.369.311 mrs., el 11,84\% del total. El menor porcentaje es el que representan los ingresos procedentes de navíos confiscados, el ancoraje coruñés o la venta de oficios diversos. Los ingresos obtenidos por estos conceptos sumaron en este período (1487-91), 868.539 mrs., lo que venía a suponer el 7,51\% del total de los ingresos.

Si nos centramos exclusivamente en el estudio de la evolución que presentan las rentas reales observamos que, a principios de los años ochenta, cuando las rentas de alcabalas de los lugares reguengos se encontraban embargadas por los oficiales reales, son los diezmos de la mar las rentas que proporcionan mayor volumen de ingresos con porcentajes comprendidos entre el $80-85 \%$ del total de las rentas reales. En los años siguientes (1487-91), la recaudación de los diezmos de la mar continuó proporcionando notables ingresos a la Hacienda Regia, aunque inferiores a los que se habían recaudado los años anteriores. Tras el levantamiento del embargo de las alcabalas de los reguengos y su concesión al prelado compostelano, fueron estas rentas las que pasaron a ocupar el primer lugar representando porcentajes que se aproximan al 60\% del total de las rentas reales. Durante estos años, los ingresos derivados de la recaudación de los diezmos de la mar pasaban a un segundo plano con porcentajes situados en torno al $36 \%$ de las rentas reales. En tercer y último lugar aparecen representados los ingresos derivados de la percepción de juros de heredad situados sobre las rentas reales de la tierra de Santiago. Las cuantías recaudadas por este concepto presentan niveles muy moderados durante el período estudiado $(4,28 \%)$, si bien a partir de 1487, una vez efectuado el desembargo de las rentas reales, los juros de los que son titulares el arzobispo y su mesa arzobispal se perciben en su totalidad y suponen unos $53.000 \mathrm{mrs}$. anuales. No obstante, el porcentaje que representan los ingresos procedentes de los juros de heredad desciende durante los años 1487-91 ante el notable incremento que experimentan las alcabalas de los lugares reguengos. 
Tabla 8: Alcabalas, diezmos de la mar y juros de heredad según los libros de recaudación (1481-91)

$\begin{array}{lcccccc}\text { Renta/s } & 1481 & \% & 1482 & \% & 1487-91 & \% \\ \text { Alcabalas } & 4.230 & 1,50 & 4.230 & 1,08 & 3.666 .347 & 59,26 \\ \text { Diezmos de la mar } & 227.368 & 81,02 & 331.996 & 85,29 & 2.254 .548 & 36,44 \\ \text { Juros de heredad } & 49.000 & 17,46 & 53.000 & 13,61 & 265.000 & 4,28 \\ \text { Total: } & \mathbf{2 8 0 . 5 9 8} & \mathbf{1 0 0} & \mathbf{3 8 9 . 2 2 6} & \mathbf{1 0 0} & \mathbf{6 . 1 0 8 . 8 9 5} & \mathbf{1 0 0}\end{array}$

Tabla 9: Comparativa de rentas reales en mrs según los libros de recaudación (1481-1491)

1481



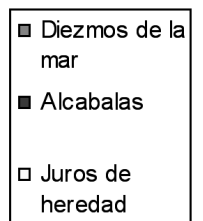

$1487-91$

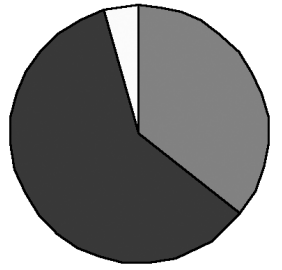

1482
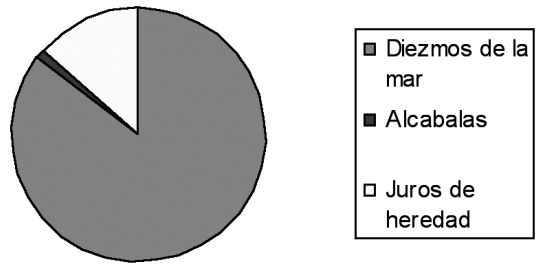